\title{
Comprehensive Insights into the Porosity of Lithium-Ion Battery Electrodes: A Comparative Study on Positive Electrodes Based on $\mathrm{LiNi}_{0.6} \mathrm{Mn}_{0.2} \mathrm{Co}_{0.2} \mathrm{O}_{2}$ (NMC622)
}

\author{
Thomas Beuse $^{1}$ (D), Mathias Fingerle ${ }^{2}$ (D) Christian Wagner ${ }^{2}$, Martin Winter ${ }^{1,3}$ and Markus Börner ${ }^{1, *(D)}$ \\ 1 MEET Battery Research Center, Institute of Physical Chemistry, University of Münster, D-48149 Münster, \\ Germany; thomas.beuse@uni-muenster.de (T.B.); martin.winter@uni-muenster.de (M.W.) \\ 2 Math2Market GmbH, D-67657 Kaiserslautern, Germany; mathias.fingerle@math2market.de (M.F.); \\ christian.wagner@math2market.de (C.W.) \\ 3 Forschungszentrum Jülich GmbH, Helmholtz-Institute Münster, IEK-12, D-48149 Münster, Germany \\ * Correspondence: markus.boerner@uni-muenster.de
}

check for updates

Citation: Beuse, T.; Fingerle, M.; Wagner, C.; Winter, M.; Börner, M. Comprehensive Insights into the Porosity of Lithium-Ion Battery Electrodes: A Comparative Study on Positive Electrodes Based on $\mathrm{LiNi}_{0.6} \mathrm{Mn}_{0.2} \mathrm{Co}_{0.2} \mathrm{O}_{2}$ (NMC622). Batteries 2021, 7, 70.

https://doi.org/10.3390/

batteries7040070

Academic Editor: Matthieu Dubarry

Received: 13 September 2021

Accepted: 20 October 2021

Published: 26 October 202

Publisher's Note: MDPI stays neutral with regard to jurisdictional claims in published maps and institutional affiliations.

Copyright: (c) 2021 by the authors. Licensee MDPI, Basel, Switzerland. This article is an open access article distributed under the terms and conditions of the Creative Commons Attribution (CC BY) license (https:// creativecommons.org/licenses/by/ $4.0 /)$.

\begin{abstract}
Porosity is frequently specified as only a value to describe the microstructure of a battery electrode. However, porosity is a key parameter for the battery electrode performance and mechanical properties such as adhesion and structural electrode integrity during charge/discharge cycling. This study illustrates the importance of using more than one method to describe the electrode microstructure of $\mathrm{LiNi}_{0.6} \mathrm{Mn}_{0.2} \mathrm{Co}_{0.2} \mathrm{O}_{2}$ (NMC622)-based positive electrodes. A correlative approach, from simple thickness measurements to tomography and segmentation, allowed deciphering the true porous electrode structure and to comprehend the advantages and inaccuracies of each of the analytical techniques. Herein, positive electrodes were calendered from a porosity of $44-18 \%$ to cover a wide range of electrode microstructures in state-of-the-art lithium-ion batteries. Especially highly densified electrodes cannot simply be described by a close packing of active and inactive material components, since a considerable amount of active material particles crack due to the intense calendering process. Therefore, a digital 3D model was created based on tomography data and simulation of the inactive material, which allowed the investigation of the complete pore network. For lithium-ion batteries, the results of the mercury intrusion experiments in combination with gas physisorption/pycnometry experiments provide comprehensive insight into the microstructure of positive electrodes.
\end{abstract}

Keywords: porosity; lithium-ion battery; positive electrode; electrode microstructure; composite electrode

\section{Introduction}

Lithium-ion batteries (LIBs) have been commercially used for three decades in a wide range of applications [1,2]. Knowledge on the processing of battery cells and their components is mostly based on empirical approaches and has not been investigated in scientific detail, yet.

An extensive investigation of the electrode microstructure is necessary not only for LIBs but also with regard to next generation batteries such as solid-state systems. A main parameter used to describe the structure of a battery composite electrode is the porosity.

A positive composite electrode is typically composed of active material (AM), a conductive agent (in this study, carbon black (CB) [3]), and a binder, altogether coated on a metallic current collector (Figure 1). Due to the evaporation of the processing solvent during drying of the electrodes, a porous structure is created with porosities depending, among others, on the solid content of the electrode paste-in this study, $44 \%$ porosity. The porosity of the positive electrode is an important parameter for battery cell performance, as it influences the percolation (electronic and ionic transport within the electrode) and the mechanical properties of the electrode such as the E-modulus and brittleness [4-8]. 
Furthermore, the porosity is key for the cell design, as it co-determines the necessary amount of electrolyte, the ideal electrode thickness depending on the operating conditions and, thus, affects energy and power densities. To adjust the porosity while maintaining a sufficient pore volume for electrolyte uptake and the associated lithium-ion transport, the electrodes are calendered.
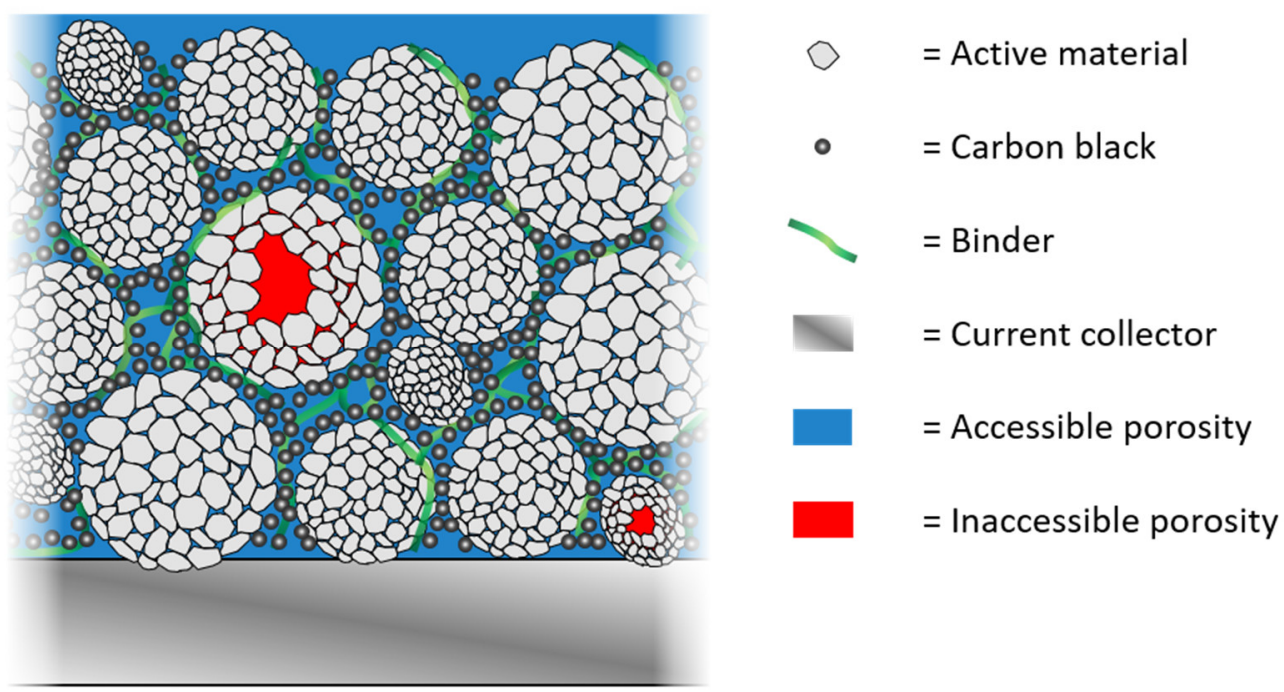

Figure 1. Scheme of the porosity, structure, and components of an electrode. The total porosity, $\varepsilon$, is the sum of $\varepsilon_{a c c}$ (blue) and $\varepsilon_{\text {inacc }}($ red).

Several methods for determining porosity have been reported in the literature, but not all methods fit for composite battery electrodes. In addition, a differentiation between the types of porosities and pore size regions is inevitable in order to decide which analysis method is most suitable, considering the systematic margin of error for each method.

\subsection{Basics of Porosity}

Porosity describes the fraction of the void volume over the total sample volume. The total porosity, $\varepsilon$, of an LIB electrode can be calculated by the ratio of the bulk density of the coated film, $\rho_{\text {bulk }}$ (including void space), to the theoretical density, $\rho_{\text {theo }}$, of the solid compounds of the coated film:

$$
\varepsilon=1-\frac{\rho_{\text {bulk }}}{\rho_{\text {theo }}}
$$

$\rho_{\text {bulk }}$ can be determined by dividing the total mass loading $\left(\mathrm{mg} \mathrm{cm}^{-2}\right)$ by the thickness of the coated film $(\mathrm{cm})$. For calculation of $\rho_{\text {theo }}$, there are two approaches: Using the skeletal density, $\rho_{\text {skel }}$, from a gas pycnometer measurement (e.g., by Schmidt et al. [6]) or the average crystallographic density, $\rho_{x t a l}$, of all electrode components (used in this study). Employing $\rho_{\text {skel }}$ instead of $\rho_{x t a l}$ results in the calculation of accessible porosity, $\varepsilon_{a c c}$, thus $\varepsilon$ is reduced by closed (=inaccessible) pores, $\varepsilon_{\text {inacc }}$. The latter (marked red in Figure 1) are inaccessible for the measurement gas and can occur, for instance, in secondary AM particles or in the case of pore sizes within the electrodes that are smaller than the molecular size of the used analysis gas. Because $\rho_{\text {skel }}$ can change during the processing of electrodes (e.g., by particle/electrode cracking, $\varepsilon_{\text {inacc }}$ may be converted into $\left.\varepsilon_{a c c}\right)$, the total porosity, $\varepsilon$, is the reference for all further porosity measurements. The electrode structure, components, and the different pores are schematically explained in Figure 1.

\subsection{Methods for Porosity Measurement}

This study focused on investigating the porosity of LIB composite electrodes coated on a non-porous current collector foil. Therefore, methods like porometry, that rely on a capillary flow through porous specimen, e.g. battery separators, are not discussed here. As mentioned in Section 1.1., the most common way to measure porosity is via the 
thickness and mass of the electrode, assuming the values for calculating $\rho_{\text {theo }}$ are known. The thickness can be measured by a gauge that also determines the accuracy of this method, because weight and area can be determined more precisely than thickness.

Determination and description of porosity via the pore size distribution (PSD) can be accomplished by small-angle scattering techniques (via X-ray or neutrons) [9,10], gas physisorption [11-14] (mostly with nitrogen), mercury intrusion porosimetry (MIP) [15-18], the Archimedes' principle with a displacement medium (e.g., water or glycerol) [19], or standard contact porosimetry $[20,21]$. The latter is based on a capillary equilibrium of any liquid between the porous sample and a standard, and it is used for pore sizes between $1 \mathrm{~nm}$ to $300 \mu \mathrm{m}$ (comparable to MIP). Except for MIP, all mentioned techniques are nondestructive.

With imaging methods, two- or three-dimensional structure models of a sample can be derived and used to determine porosity and PSD. Scanning electron microscopy (SEM) can be applied for surface and cross-sectional analysis (2D) [6,22,23]; combined with a focus ion beam (FIB), it can result in FIB/SEM tomography (3D) [24-27]. Nondestructive tomography techniques utilize neutrons or X-ray radiation [26,28-31] and can visualize a larger sample volume than FIB/SEM (e.g., $500 \times 110 \times 250 \mu \mathrm{m}$ compared to $31.3 \times 34.5 \times 16.8 \mu \mathrm{m}$ [26]) but with a lower resolution (e.g., a voxel edge length of $438 \mathrm{~nm}$ compared to $33.6 \mathrm{~nm}[26]$ ), depending on the setup.

Recently, digital modeling of electrode structures and manufacturing processes has become more relevant [5,32]. From different electrode paste compositions to calendering and electrochemical performance, several microstructures and the resulting porosities can be investigated. In the future, artificial intelligence could, on the basis of the fundamental understanding of the correlation between materials, microstructure, and electrochemical performance, enable model-based identification of the most suitable microstructures for a specific application [33]. This study is one step toward achieving this fundamental understanding of the experiments.

Modeling, especially, shows the challenges of understanding the microstructure of an electrode. The total porosity is only one parameter to characterize the morphology of electrodes after calendering. For the same value for total porosity of different electrodes, the distribution of $\mathrm{AM}, \mathrm{CB}$, binder, and pores could be heterogeneous and result in different structural properties and, ultimately, diverse electrochemical performances. The shape of the pores and pore connectivity affect the electronic as well as the ionic conductivity [34]. Moreover, attention should be paid to the influence of inactive materials (IMs) (i.e., CB and binder) on the microstructure and the transport phenomena within the electrode. Since these two components cannot often be considered separately from each other, they are usually described as a unit: the carbon and binder domain (CBD).

Underestimating the importance of the CBD is frequently the reason for large differences between electrochemical experiments regarding Li-ion conductivity in positive electrodes and digital model electrodes derived from tomography measurements or those that are digitally generated [27,35-37]. Therefore, detailed analysis of porosity, PSD, and structural heterogeneity is necessary and must be performed for each change in the parameters (e.g., electrode composition or manufacturing process). State-of-the-art positive electrodes contain only 2 to $5 \mathrm{wt} \%$ of IMs and possess a porosity below $30 \%$. Hence, results from the literature $[6,17,23]$ for electrodes with higher IM content and/or higher porosity cannot be directly transferred to state-of-the-art electrodes. For determining porosity, often only one method is applied, although values for porosity can differ significantly depending on the method. The prediction of the electrochemical performance of positive electrodes requires a further structural property, the tortuosity. This factor and its impact on electrochemical performance is currently under investigation and will be published shortly.

This study compared different methods and their margin of error for microstructural investigations covering the range of pore sizes from micro- $(<2 \mathrm{~nm})$ or meso- $(2-50 \mathrm{~nm})$ 
to macropores (>50 nm) [14]. The investigated samples were state-of-the-art positive electrodes with a wide range of porosity (from $<20 \%$ to $>40 \%$ ).

\section{Materials and Methods}

The positive electrodes consisted of $95 \mathrm{wt} \% \mathrm{AM}\left(\mathrm{LiNi}_{0.6} \mathrm{Mn}_{0.2} \mathrm{Co}_{0.2} \mathrm{O}_{2}\right.$ (NMC622), BASF, $\rho_{\text {xtal }}($ measured $\left.)=4.76 \mathrm{~g} \mathrm{~cm}^{-3}\right), 2 \mathrm{wt} \%$ CB (SuperC65, Imerys, $\rho_{x t a l}($ measured $\left.)=2.25 \mathrm{~g} \mathrm{~cm}^{-3}\right)$, and $3 \mathrm{wt} \%$ of polyvinylidene difluoride (PVdF, Kureha, $\rho_{\text {theo }}=1.77 \mathrm{~g} \mathrm{~cm}^{-3}$ ) binder. The components were mixed and homogenized with the solvent N-methyl-2-pyrrolidone (NMP) in an intensive mixer Labormischer R02 VAC (EIRICH EVACTHERM) and coated on an aluminum current collector from UACJ. The areal capacity was set to $4 \mathrm{mAh} \mathrm{cm}^{-2}$. By means of calendering, the electrodes were set to five different porosities from uncalendered $(\approx 44 \%)$ to $18 \%$. Calendering was performed using a hydraulic roll-press calender (CLG-ZM-300Y) with varying loads of up to $1500 \mathrm{kN}$ (maximum load as specified by the manufacturer) for the lowest porosity of $18 \%$.

The porosity investigation of the electrodes was performed with the same samples of each porosity (punched to $12 \mathrm{~mm}$ diameter) for all methods, starting with non-destructive techniques and ending with MIP. The total porosity, $\varepsilon$, was determined with a gauge for at least 60 samples for each porosity. The specific surface areas of the electrodes and pore sizes up to $400 \mathrm{~nm}$ were measured with nitrogen ad-/desorption on a Micromeritics ASAP 2020 Surface and Porosity Analyzer (degassing at $120{ }^{\circ} \mathrm{C}$ for $12 \mathrm{~h}$ ). The amount of coating material ranged from 3-4 g. The specific surface area was determined by the BrunauerEmmett-Teller (BET) method [11], and the PSD was calculated with the model of Barrett, Joyner, and Halenda (BJH) [12]. Skeletal density $\rho_{\text {skel }}$ (and $\varepsilon_{\text {inacc }}$ ) was determined with a helium pycnometer (Micromeritics AccuPyc II 1340) after three measurements with ten cycles each: three measurements to obtain converging results and ten measurements within these three cycles for statistics and trends. The values for $\rho_{\text {skel }}$ were used for calculations in MIP. The latter was performed on 60 samples using a Pascal 140-440 (Pressurization by Automatic Speed-up and Continuous Adjustment Logic) porosimeter (Thermo Fischer Scientific (Waltham, MA, USA); distribution by Porotec $\mathrm{GmbH}$ ). The pressure range was set to $0.01-400 \mathrm{MPa}$, whereas pore radii in the range of $110-0.0037 \mu \mathrm{m}$ can be determined (based on the Washburn model [15]). The porosimeter procedure consisted of two steps: a low-pressure region from $0.01-0.4 \mathrm{MPa}(110-3.6 \mu \mathrm{m}$ pore size) and after a sample transfer a high-pressure region from $0.1-400 \mathrm{MPa}(13-0.0037 \mu \mathrm{m})$. Since the D90 value of the AM secondary particles was determined to be $14 \mu \mathrm{m}$, which defines the pore sizes in the electrode, the evaluation of the mercury intrusion data was limited to the high-pressure region. Larger voids $(13-110 \mu \mathrm{m})$ were attributed to the space between the samples in the dilatometer [17]. The mercury in the capillary formed a plate capacitor with the metal sleeve around the dilatometer, the capacitance of which was proportional to the height of the mercury column in the metal sleeve. The intrusion of mercury into the sample was measured by a change in capacitance. Analysis of the MIP results was performed using the SOLID software (Solver of Intrusion Data, version 1.2.1), which included a calculation of the specific surface areas of the electrodes based on the PSD and a pore shape model. Possible pore shapes within the software were cylindrical/plate, conical, and spherical.

For surface, cross-sectional, and tomography images via SEM and FIB an AURIGA Crossbeam workstation from Zeiss with a field emission gun (Schottky-type) was used. The tomography was prepared by a FIB milling process, using a high brightness liquid gallium ion source. For the two-dimensional cross-sections, the samples were embedded in an epoxy-resin (Epofix, Struers), cut, and polished with different polishing cloths in combination with a diamond suspension of 9,3 , and $1 \mu \mathrm{m}$ (Tegramin, Struers). The acceleration voltage of the SEM was adjusted to 1.5 (tomography) and $3 \mathrm{kV}$ for investigation of the particles' surface and the CBD and to $15 \mathrm{kV}$ for AM and for particle cracking visualization in the cross-sectional images of the embedded electrodes. Three-dimensional surface images and quantification of electrode surface densification were performed by a confocal laser scanning microscope (VK-X200, Keyence, Osaka, Japan) (CLSM). 
For the FIB/SEM image segmentation and digital modeling, the FIB/SEM image data were segmented and processed using the GeoDict2020 software by Math2Market GmbH. A filter to remove the so-called curtaining-effect was applied. A non-local means filter was applied to reduce noise. The misalignment of the image stack was corrected using a specially designed algorithm. Since it was not possible to segment the CBD from the AM and the pore space, the segmentation was focused on segmenting the AM, while assigning the $\mathrm{CBD}$ as pore. Afterwards, the $\mathrm{CBD}$ was digitally modeled into the microstructure. The known information about the $\mathrm{CBD}$ regarding the density and weight percent for this specific sample was combined with general values from the literature for porosity, PSD, cluster distribution, and tortuosity [27]. Firstly, the CBD was created as a non-porous phase and was distributed via a geometric algorithm in the pore space, connecting the active material with a contact angle of $40^{\circ}$ between AM and CBD. Different approaches modeling the CBD have recently been reported [36]. Afterwards, the porosity of the CBD was modeled in an additional step using previously published information [27] and a fibrous base shape of the pores with a Gaussian diameter distribution. The porosity of the CBD phase was $50.2 \%$ with a minimal pore diameter of $37.2 \mathrm{~nm}$, which is equivalent to the modeled voxel length. MIP and granulometry (mathematical description of the pore size by filling the pores with spheres) were simulated using PoroDict in the GeoDict software $[38,39]$ with a batch size of the voxel length. The composition of the electrodes in $\mathrm{wt} \%$ and $\mathrm{vol} \%$ with the used densities are given in Table 1 . The solid-volume-percentage and density of the combined $\mathrm{CB}$ and binder to CBD is also shown.

Table 1. Composition of the positive electrodes and the used densities for AM, CB, and binder. The $\mathrm{CB}$ and binder were combined to the $\mathrm{CBD}$.

\begin{tabular}{cccc}
\hline & NMC622 & CB & PVdF \\
\hline Weight-Percentage (\%) & 95 & 2 & 3 \\
\hline $\begin{array}{c}\text { Solid-Volume-Percentage } \\
(\%)\end{array}$ & 88.54 & $3.9411 .46(\mathrm{CBD}) 7.52$ \\
\hline Density $\left(\mathrm{g} / \mathrm{cm}^{3}\right)$ & 4.76 & $2.251 .935(\mathrm{CBD}) 1.77$ \\
\hline
\end{tabular}

\section{Results and Discussion}

\subsection{Comparison of Porosity Investigation Methods}

In Figure 2, the characterization methods for the microstructures of the positive electrodes are summarized and sorted according to the required sample amount for an accurate measurement. Therein, the comparatively large sample volume for the different methods, except SEM, has the advantage of yielding representative results by analyzing a complete electrode sheet with a size of approximately $150 \mathrm{~cm}^{2}$. The width of the bars represents the range of pore sizes that can be investigated with the corresponding technique. Most of them are physically limited (e.g., by the size of the $\mathrm{N}_{2}$-molecule or the pressure range of MIP), while the upper and lower limits of the FIB/SEM tomography technique were determined by a combination of desired resolution, sample volume, and measurement time. He-pycnometry does not directly measure the pores within the electrode, but helium gas penetrates all accessible pores (> kinetic diameter of $\mathrm{He}$ ), and by measuring $\rho_{\text {skel }}$ and comparing with $\rho_{x t a l}$, it allows the determination of the amount of closed pores. This method has no upper pore size limit. 


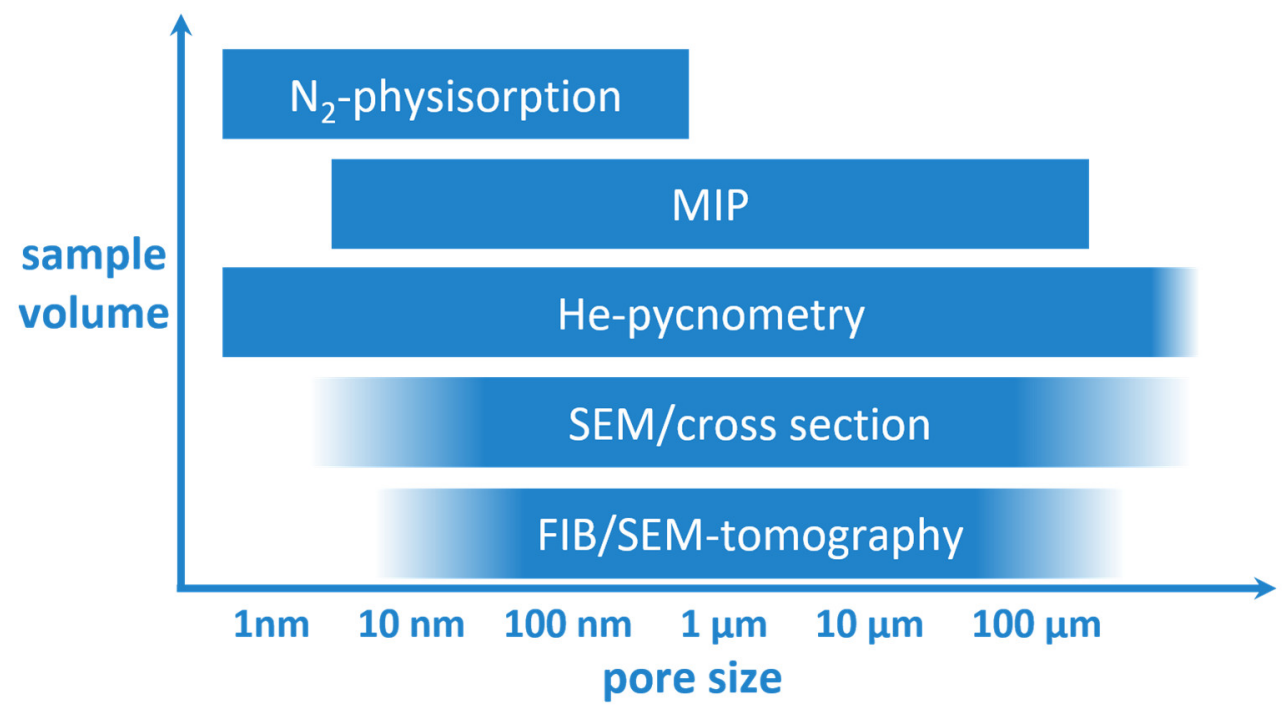

Figure 2. Overview of porosity investigation methods used in this work: The required sample volume is small for FIB/SEM and much larger for the other analysis techniques. The $x$-axis shows the measurable pore sizes of the methods. The gas physisorption and expansion methods have lower limits determined by the size of the gas molecules. The $\mathrm{N}_{2}$ molecular cross-sectional area was $0.162 \mathrm{~nm}^{2}$ and the He kinetic diameter is $0.26 \mathrm{~nm}[14,40]$. MIP was simply limited in both directions by the pressure range of the device (see experimental part), where the pore range of the last two methods based on SEM depends on the setup, operation conditions, and the sample properties.

As an example, for the investigated microstructural features in dependence of the respective methods, Figure 3 shows an embedded cross-section of a positive electrode. The CBD (not visible) fills most of the voids between the AM particles. With the gauge, only the highest electrode thickness value can be measured, including the current collector.

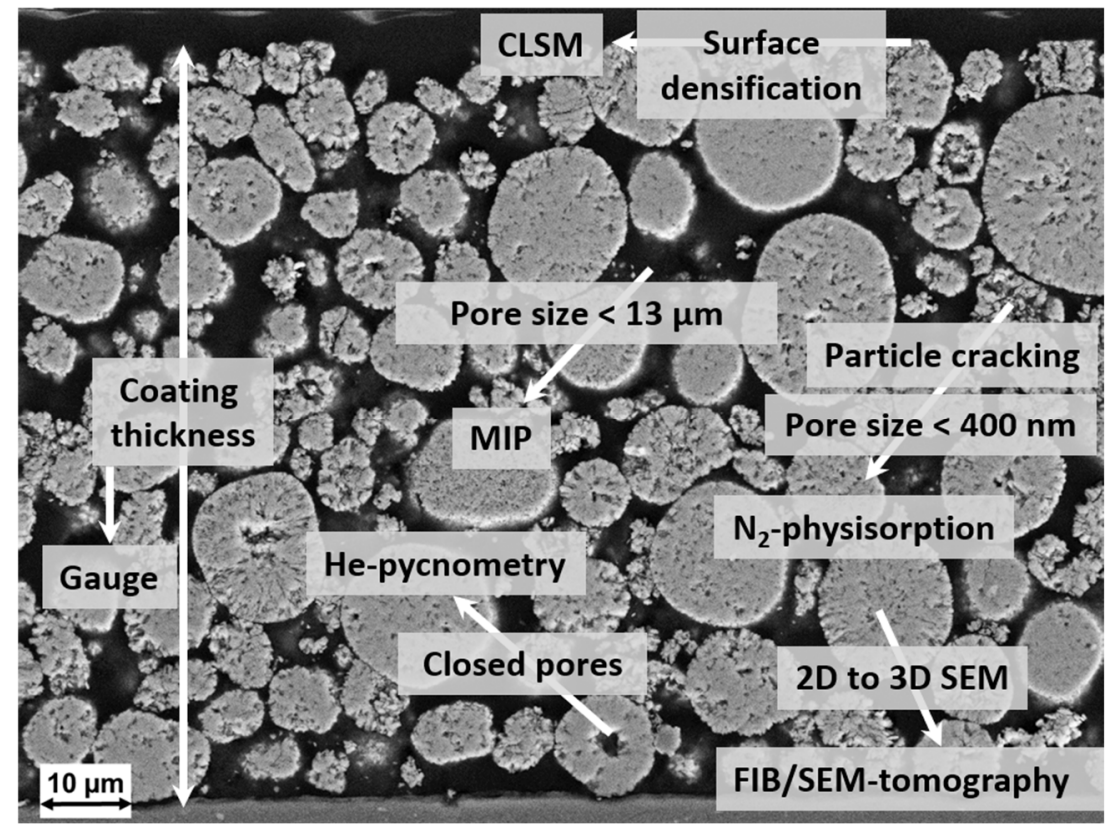

Figure 3. Cross-section of a positive electrode with a porosity of $30 \%$ embedded in epoxy resin. At the bottom, the aluminum current collector is visible. The measurement methods were assigned to their corresponding microstructural features.

The compaction of the electrode to $30 \%$ porosity resulted in the cracking of several AM secondary particles. This led to an increase in the inner surface area and created pores 
in the nanometer range, which can be measured by $\mathrm{N}_{2}$-physisorption. Particle cracking at the surface and clogging of surface pores with CBD caused a densification of the electrode surface, which can be identified by SEM or quantified via CLSM. The closing of surface pores with CBD is also described by Haselrieder et al. and Günther et al. as an effect of high densification of the electrodes [41,42]. The closed pores inside the AM secondary particles led to a difference between $\rho_{\text {skel }}$ and $\rho_{\text {xtal }}$ that can be measured by He-pycnometry. Most of the accessible pores within the composite electrode were in the measurable range of MIP. To verify all of the described microstructural features and effects, FIB/SEM tomography was necessary to create a 3D model of the electrode.

As a reference measurement for all further methods, the thicknesses of the electrodes determined with a gauge were used to calculate the total porosity. The uncalendered electrodes had a porosity of $44 \%$. After calendering, porosities of $39 \%, 30 \%, 26 \%$, and $18 \%$ were produced. To verify the reproducibility of the results, an electrode sheet, which was identically processed as the one with $30 \%$ porosity, was additionally considered. The total porosity of electrodes from this sheet was $28 \%$ (gauge measurement). The corresponding electrode densities, $\rho_{\text {bulk }}$, ranged from $2.47 \mathrm{~g} \mathrm{~cm}^{-3}$ (uncalendered) to $3.65 \mathrm{~g} \mathrm{~cm}^{-3}(18 \%$ porosity). Measuring 60 electrodes each, the standard deviation (=statistic error) was the largest for the electrode with the lowest porosity $(18 \pm 1.6 \%)$ and the smallest for the uncalendered electrode $(44 \pm 0.7 \%)$. This finding was attributed to the larger absolute influence of the inaccuracy of the gauge $( \pm 1 \mu \mathrm{m})$ for the thinner electrodes. Therefore, the systematic error of the measured porosity originating from the gauge was only $\pm 0.6 \%$ for the electrode with the highest porosity and with an electrode thickness of $94 \pm 1 \mu \mathrm{m}$ but $\pm 1.3 \%$ for the electrode with the lowest porosity $(64 \pm 1 \mu \mathrm{m})$. Considering the natural thickness inhomogeneity of the electrodes and the systematic error of the thickness measurement, the according overall standard deviation amounted to $0.7-1.6 \%$ porosity.

Consequently, the porosity values are specified as integer values, as accuracy to the decimal place cannot be reasonably accomplished for composite electrodes. This is important when comparing the results and errors of the different methods in this study and to values in the literature. A difference of $1-2 \%$ in porosity cannot be considered significant for most analytical methods. Therefore, the difference between the two identically processed electrodes with $30 \%$ and $28 \%$ porosity can be considered negligible as the deviations were within the margin of error.

\subsection{Scanning Electron and Laser Microscopy}

To evaluate the influence of calendering on the microstructure of electrodes in the crosssectional and surface profiles, the results for uncalendered electrodes and for electrodes with the lowest porosity of $18 \%$ are discussed. Figure 4 shows the SEM cross-sections and CLSM top view of these two electrodes ( $44 \%$ and $18 \%$ porosity). With the same height scale in the CLSM images, a significantly smoother surface of the calendered sample is visible. The compression to $18 \%$ porosity resulted in a decrease in the electrode surface roughness (root mean square) by a factor of 3.5 from $2.59 \pm 0.12 \mu \mathrm{m}$ for $44 \%$ porosity to $0.74 \pm 0.04 \mu \mathrm{m}$ for $18 \%$ porosity. Considering the lateral resolution of the CLSM method, a $50 \%$ reduction in the effective surface area can be observed when the porosity was decreased from $44 \%$ to $18 \%$ porosity. While the smoothening of the electrode surface could result in a more homogeneous current distribution at the electrode surface, it can also negatively influence the Li-ion mobility on the surface of the porous electrode structure by reducing electrolyte accessibility and rate capability as well as the electrolyte wetting behavior of the electrodes during cell production. The speed of electrolyte uptake decreases with smaller and fewer access areas for the electrolyte, since some closing of the surface pores occurs with high electrode compression [42]. Beyond that, low porosities lead to an increased tortuosity which cause prolonged Li-ion migration/diffusion pathways that can reduce the electrode rate capability. Thus, depending on the application and the operating conditions, the advantages or drawbacks of a denser electrode surface predominate in terms of increased 
energy density and homogeneous current distribution or reduced accessibility and rate capability, respectively.
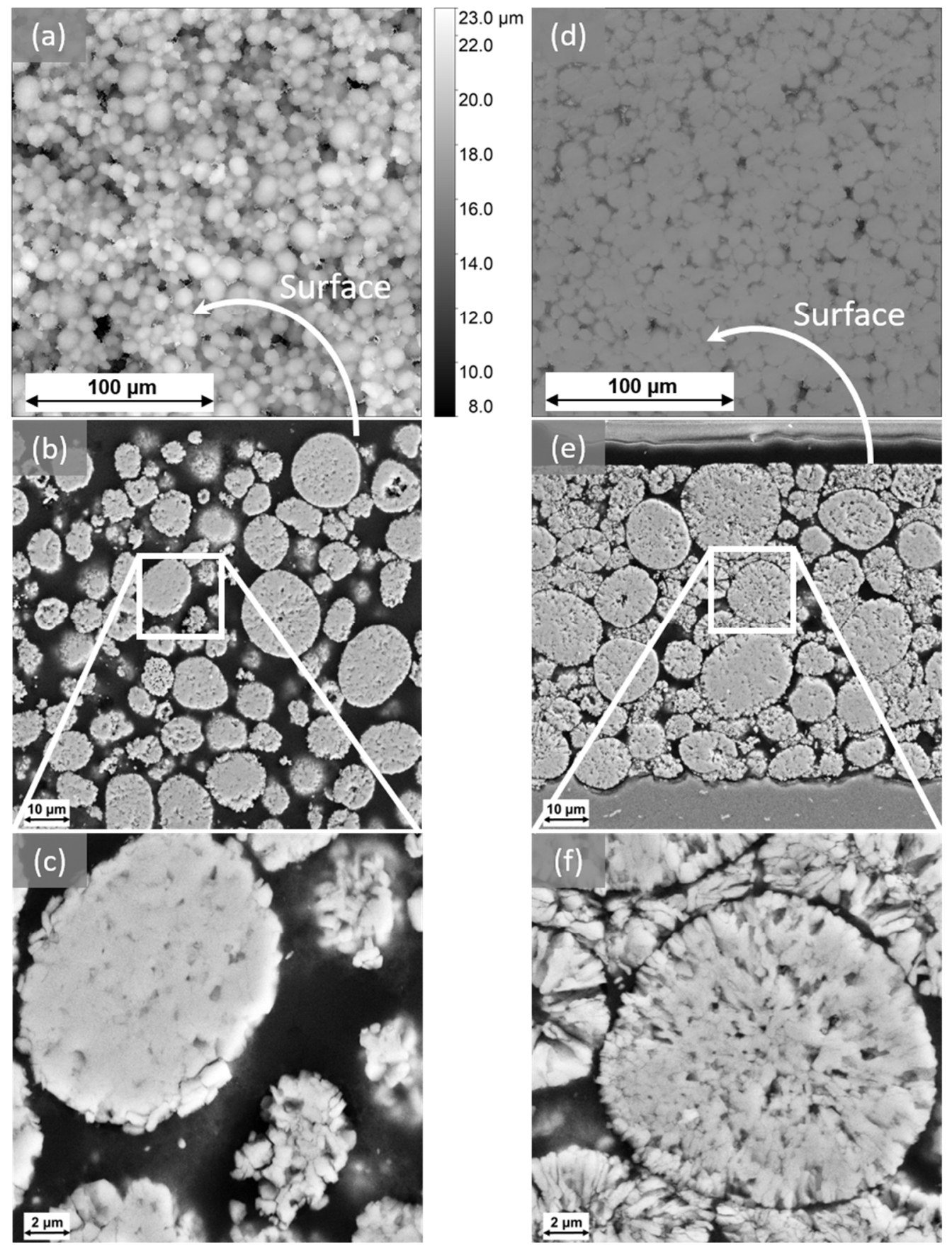

Figure 4. SEM cross-sections and CLSM top views (a-d) of positive electrodes with the highest (44\%) $(\mathbf{a}-\mathbf{c})$, and lowest $(18 \%)(\mathbf{d}-\mathbf{f})$, porosity.

The SEM images of the uncalendered electrode showed almost no cracking or deformation of the AM secondary particles. Few exceptions can originate from AM production or electrode paste processing. The mean particle size of the AM was $10 \mu \mathrm{m}$ with a range from 1 to $20 \mu \mathrm{m}$ in diameter. The homogenous distribution of CBD and the differentiation between CBD and pores are shown in the Supplementary Material (Figure S1). A few AM secondary particles show voids, which can be assigned to closed pores or to some extent to material removal by sample preparation. 
Decreasing the porosity to $18 \%$, the thickness of the electrode was reduced from 94 to $64 \mu \mathrm{m}$ (without an aluminum current collector, visible at the bottom of Figure 4e). Due to the high calendering pressure, the AM particles were pressed into the metal foil, which improves the adhesion and decreases the electronic contact resistance between the composite electrode and current collector [23]. Approximately half of the AM secondary particles were cracked to achieve the high density of the electrode, while at the surface, nearly all particles were deformed/cracked. Pore sizes were mostly below $1 \mu \mathrm{m}$, considering that CBD filled most of the voids between the AM particles (see Figure S1).

Both electrodes had a homogenous distribution of AM and particle sizes as well as a uniform densification in the case of the calendered electrode. At some positions, the higher thickness values of the cross-section compared to gauge measurements can be explained as follows. Firstly, charging effects of the epoxy resin in the electron beam can lead to drifting effects due to the electrostatic deflection of the beam during SEM characterization. Secondly, the cutting angle can deviate from 90 degrees with respect to the electrode within the resin block, leading to a misinterpretation considering the electrode thickness.

Thus, sample preparation can be considered as the main source of error for the SEM cross-sectional measurement. A further drawback are the limitations of 2D imaging. Without 3D information, closed pores or cracks within the AM secondary particles could also arise in the polishing step during cross-section preparation.

The microscopy methods provide a qualitative overview of the microstructural features relevant for the evaluation of LIBs with respect to the electrochemical performance. In particular, the compression of the electrode after calendering and the associated changes in the AM particle structure can be depicted. In addition, a first quantitative description of the densification is accessible with CLSM (limited to the electrode surface).

\subsection{He-Pycnometry}

To measure the skeletal density, $\rho_{\text {skel }}$, of the electrodes and the AM powder, Hepycnometry measurements were performed. By comparing $\rho_{\text {skel }}$ with $\rho_{x t a l}$, the closed porosity $\varepsilon_{\text {inacc }}$ could be determined. Closed pores, as shown in Figure 5(c2), can be located in AM secondary particles, in CBD agglomerates, between CBD and AM particles, or between AM particles. The latter could occur especially after strong calendering in combination with particle cracking.

The results for $\rho_{\text {skel }}$ ranged between $4.27 \mathrm{~g} \mathrm{~cm}^{-3}$ for the uncalendered electrode and $4.31 \mathrm{~g} \mathrm{~cm}^{-3}$ for the lowest porosity electrode. As the uncertainty was up to $\pm 0.01 \mathrm{~g} \mathrm{~cm}^{-3}$, the difference with regard to $\rho_{\text {skel }}$ for the variation in porosities can be considered to be insignificant. Comparing $\rho_{\text {skel }}$ with $\rho_{x t a l}\left(4.436 \mathrm{~g} \mathrm{~cm}^{-3}\right)$ provides the amount of closed pores inside the solid volume of the electrode, which was between $3.7 \%$ and $2.8 \%$ (highest to lowest porosity). This amount agrees with the measurement of $\rho_{\text {skel }}\left(4.61 \mathrm{~g} \mathrm{~cm}^{-3}\right)$ and $\rho_{\text {xtal }}$ $\left(4.76 \mathrm{~g} \mathrm{~cm}^{-3}\right)$ of the pristine AM powder. Here, the void space inside the AM particles was determined to be $3.2 \%$. To some extent, the polycrystallinity of the AM also decreased its density in comparison to $\rho_{x t a l}$. The main contribution of the difference between $\rho_{\text {skel }}$ and $\rho_{x t a l}$ of the AM remains the pores inside the AM particles as visualized in the SEM cross-sections (see Figure 3). By He-pycnometry, the pores in the AM can be quantified.

The increase in $\rho_{\text {skel }}$ with lower porosity could be due to the particle cracking of the AM. With this, the He-gas obtains access to originally closed pores. A counteracting effect could be the creation of new closed pores due to the intense calendering, especially within the CBD. However, due to the high amount of particle cracking at low total porosity identified in the SEM images, this was assumed to be the dominant effect for changes in $\rho_{\text {skel }}$. 
(a)

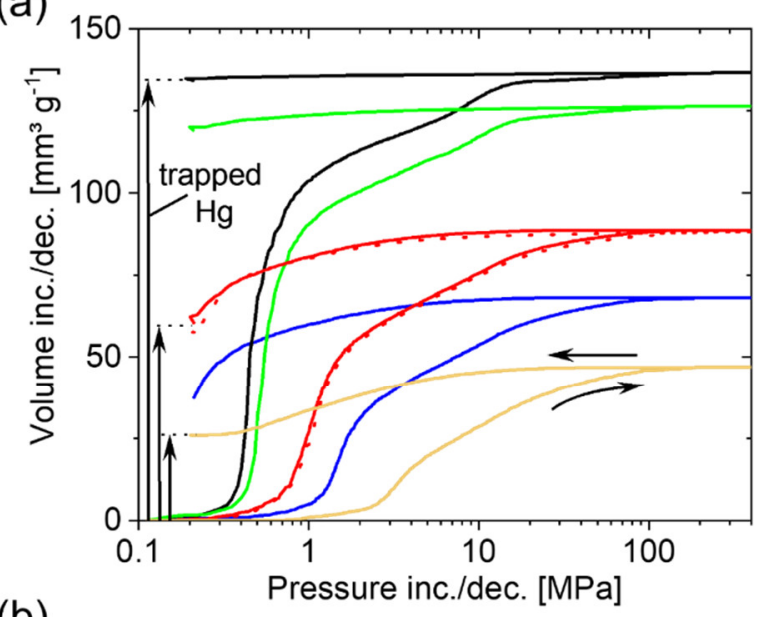

(b)

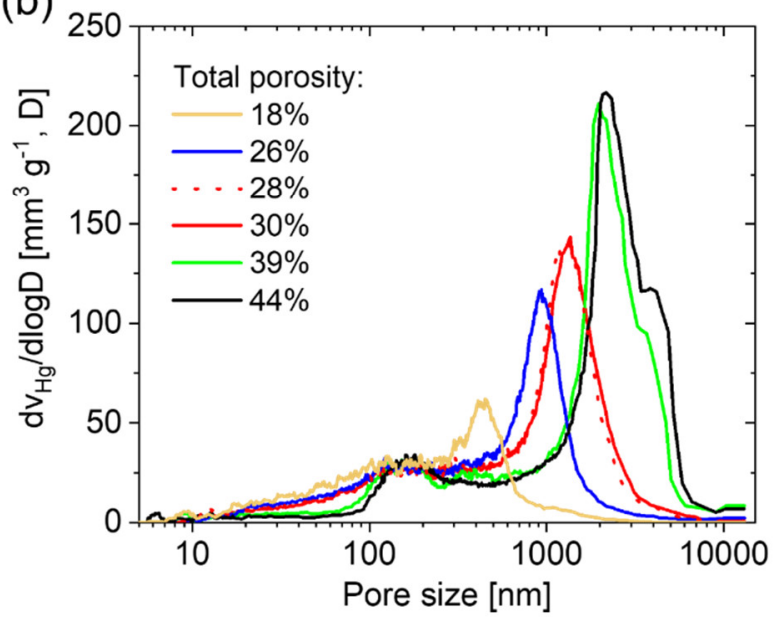

(c)

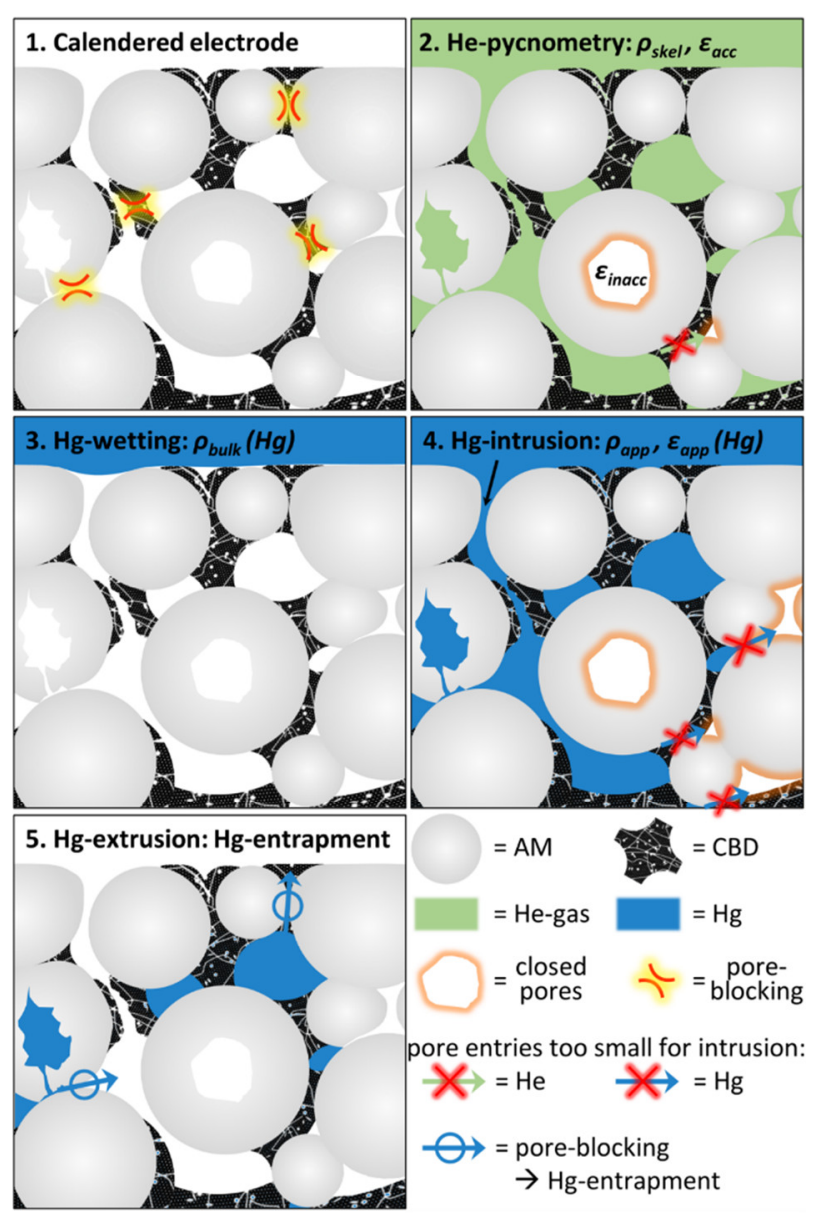

Figure 5. MIP results: (a) intruded/extruded specific $\mathrm{Hg}$-volume, $v_{\mathrm{Hg}}$, during pressure increase/decrease. The shape of the curves during decreasing pressure contains information about the pore shape with less trapped mercury for lower porosities; (b) PSD: a shift in the mean pore size to smaller values and an increase in pore volume for pores $<100 \mathrm{~nm}$ for lower porosity; (c) schematic representation of a porous electrode during He-pycnometry and MIP and the corresponding densities and porosities that can be measured/calculated. MIP is shown as a 3 step process with wetting, intrusion, and extrusion in addition to the resulting Hg-entrapment.

The results for $\rho_{\text {skel }}$ ranged between $4.27 \mathrm{~g} \mathrm{~cm}^{-3}$ for the uncalendered electrode and $4.31 \mathrm{~g} \mathrm{~cm}^{-3}$ for the lowest porosity electrode. As the uncertainty was up to $\pm 0.01 \mathrm{~g} \mathrm{~cm}^{-3}$, the difference with regard to $\rho_{\text {skel }}$ for the variation in porosities can be considered to be insignificant. Comparing $\rho_{\text {skel }}$ with $\rho_{x t a l}\left(4.436 \mathrm{~g} \mathrm{~cm}^{-3}\right)$ provides the amount of closed pores inside the solid volume of the electrode, which was between $3.7 \%$ and $2.8 \%$ (highest to lowest porosity). This amount agrees with the measurement of $\rho_{\text {skel }}\left(4.61 \mathrm{~g} \mathrm{~cm}^{-3}\right)$ and $\rho_{\text {xtal }}$ $\left(4.76 \mathrm{~g} \mathrm{~cm}^{-3}\right)$ of the pristine AM powder. Here, the void space inside the AM particles was determined to be $3.2 \%$. To some extent, the polycrystallinity of the AM also decreased its density in comparison to $\rho_{x t a l}$. The main contribution of the difference between $\rho_{\text {skel }}$ and $\rho_{x t a l}$ of the AM remains the pores inside the AM particles as visualized in the SEM cross-sections (see Figure 3). By He-pycnometry, the pores in the AM can be quantified.

The increase in $\rho_{\text {skel }}$ with lower porosity could be due to the particle cracking of the AM. With this, the He-gas obtains access to originally closed pores. A counteracting effect could be the creation of new closed pores due to the intense calendering, especially within the CBD. However, due to the high amount of particle cracking at low total porosity identified in the SEM images, this was assumed to be the dominant effect for changes in $\rho_{\text {skel. }}$. 
In contrast to calculating closed pores inside the solid volume, calculating $\varepsilon_{\text {inacc }}$ also took the void volume inside the electrodes into consideration, which then resulted in closed porosities of $2.2 \% / 2.1 \% / 2.6 \% / 2.3 \% / 2.4 \%$ (highest to lowest total porosity $\varepsilon$ ). The highest value for $\varepsilon_{\text {inacc }}$ was calculated for electrodes with $\varepsilon=30 \%$. This was confirmed by reference electrodes with $\varepsilon=28 \%$ and $\varepsilon_{\text {inacc }}=2.6 \%$. Considering the margin of error of $\rho_{\text {skel }}$, the uncertainty for $\varepsilon_{\text {inacc }}$ was 0.2 percentage points. Thus, the difference in $\varepsilon_{\text {inacc }}$ among the different porous electrodes was not significant.

As a consequence of the calculation of $\varepsilon_{\text {inacc }}$, the accessible porosity, $\varepsilon_{a c c}$, was for all electrodes more than two percentage points lower than $\varepsilon$, which affected the pore volume in the electrode that could be filled by electrolyte.

In addition to the rational results for $\rho_{\text {skel }}$, errors in the measurement technique should be considered. The measured sample volume increased during the first two measurement steps (procedure described in Section 2) and stabilized afterwards. Nguyen et al. studied ideal measurement conditions for different material classes (e.g., nonporous silicon and porous zeolite material) and the influence of activation (=drying) of the samples, the number of cycles, and percentage fill volumes (sample volume compared to volume of the measuring chamber) [40]. Since the electrodes in our study were dried during sample preparation for $\mathrm{N}_{2}$-physisorption measurements, the amount of residual moisture within the porous electrode structure was expected to be negligible. Before starting the pycnometry measurement, the samples were briefly exposed to the lab atmosphere during sample transfer (sample preparation in a dry room), possibly causing deviations during the first measurement cycles. The small kinetic diameter of He of $0.26 \mathrm{~nm}$ enables diffusion of the gas into the different electrode materials, especially into the CBD [40]. However, changing to a larger or even non-inert gas molecule, such as $\mathrm{N}_{2}$, would result in larger errors. The annulus volume, which is the volume between the surface of the electrode materials and the closest distance at which the gas molecules approach it, would increase and the ad-/desorption of $\mathrm{N}_{2}$ by the sample would result in incorrect pressure readings [40]. Another source of inaccuracy is the subtraction of the volume of the aluminum current collector, which was determined in a separate measurement. This additional measurement was performed with pristine foil.

The pycnometry measurement was necessary to calculate $\varepsilon_{a c c}$, which describes the maximum pore volume that can be filled with electrolytes. According to the results of this study, 2-3\% less electrolyte was needed than expected from the total pore volume within the electrodes. In addition, the closed pores within the solid phase could influence the mechanical properties of the electrodes (e.g., volume expansion of AM during de/lithiation), and measuring a variation of these pores for differently compressed electrodes could be a sign of structural changes such as particle cracking of the AM.

\subsection{Mercury Intrusion Porosimetry and $\mathrm{N}_{2}$-Physisorption}

The most common technique to investigate the porosity and especially the PSD of LIB electrodes is MIP. As shown in Figure 2, MIP covers nearly all pore sizes, which occur in electrodes of LIBs besides micropores. The results of the intrusion experiments are shown in Figure 5. The specific volume of mercury $(\mathrm{Hg}), v_{\mathrm{Hg}}$, within the electrodes during in-/extrusion is depicted in Figure 5a. From the intrusion data, the PSD (Figure 5b) can be calculated, assuming $\mathrm{Hg}$ is a perfect non-wetting liquid with a constant contact angle to the electrode material surface. Releasing pressure after intrusion results in an extrusion of $\mathrm{Hg}$ from the electrode. This process is influenced by the shape and size of the pores. For uncalendered electrodes, nearly all the intruded $\mathrm{Hg}$ stays trapped in the electrode after pressure release, while only half of the $\mathrm{Hg}$ remains inside in case of electrodes with the lowest porosity (marked in Figure 5a). One reason could be the change in pore shape from spherical (for uncalendered electrodes) to more conical-like pores (for lower porosities). Spherical pores have a larger ratio of pore body size to pore throat size, which increases the amount of Hg-entrapment [43]. Rigby and Edler suggest further reasons for the $\mathrm{Hg}$ entrapment being spatially extended structural heterogeneities, a snap-off in narrow pores 
located next to much larger pore elements (marked in Figure 5(c5)), and the contact angle hysteresis [43].

A change in pore shape, even at constant porosity, alters the electronic and ionic conductivity of battery electrodes [34]. Thus, the pore shape directly influences the electrochemical performance of LIBs and electrodes. Furthermore, the surface area of pores increases when changing from spherical to more conical and slit-like pores. This is important for interface chemistry (electrolyte additive research) and for calculating the ionic conductivity of the electrolyte within the electrode (tortuosity, currently under investigation). Additional insights are expected when comparing MIP and $\mathrm{N}_{2}$-physisorption, discussed hereafter.

More structural heterogeneities of uncalendered electrodes compared to calendered electrodes and, therefore, a higher amount of Hg-entrapment can be confirmed with the PSD results in Figure 5b. The PSD graph shows the differential specific pore volume with respect to the logarithm of the pore diameter $\left(d v_{\mathrm{Hg}} / d \log D\right)$ as a function of the pore size. A bimodal distribution can be identified for all investigated electrode porosities with a major fraction of pore sizes (highest peak) at $3 \mu \mathrm{m}$ for uncalendered electrodes. This peak shifts to smaller pore sizes for lower electrode porosities down to nearly $400 \mathrm{~nm}$ for electrodes with $18 \%$ total porosity. A second peak at $\approx 100 \mathrm{~nm}$ stays almost constant for all investigated electrode porosities and can be attributed to pores within or between CBD clusters [27]. At pore sizes below $100 \mathrm{~nm}$, the specific pore volume increases for the lower porosity electrodes. The reasons for this increase are, on the one hand, the compression of larger pores, and on the other hand the creation of smaller pores resulting from AM particle cracking, starting here at $30 \%$ porosity towards lower porosities.

The peak shift with lower porosity results in a decrease in structural heterogeneities because the PSD becomes more uniform. Contrary to this, the increase in the number of pores below $100 \mathrm{~nm}$ for the electrode with the lower porosity and the overall densification of the electrode resulted in a more tortuous pore network and, thus, a lower effective ionic conductivity within the electrode/electrolyte assembly.

In addition to the PSD, the bulk sample volume, $V_{\text {bulk }}(\mathrm{Hg})$, can be measured after covering the electrodes with $\mathrm{Hg}$ and before applying a pressure for intrusion, since $\mathrm{Hg}$ is considered to be a perfect non-wetting liquid. With $V_{b u l k}(\mathrm{Hg})$ and the sample mass, $m_{\text {sample }}, \rho_{\text {bulk }}(\mathrm{Hg})$ can be calculated. Furthermore, the total amount of intruded $\mathrm{Hg} V_{\mathrm{Hg}}$ yields information considering $\varepsilon_{a c c}$ down to pore sizes of $3.7 \mathrm{~nm}$. Reducing $V_{b u l k}(\mathrm{Hg})$ by $V_{\mathrm{Hg}}$ results in the apparent density $\rho_{\text {app }}$.

$$
\rho_{\text {app }}=\frac{m_{\text {sample }}}{V_{\text {bulk }}(H g)-V_{H g}}
$$

If the electrodes show no structural changes during MIP (e.g., no compression) and contain no pore throats with a size $<3.7 \mathrm{~nm}, \rho_{\text {app }}$ should be close to $\rho_{\text {skel }}$ (determined by He-pycnometry). By applying the different densities, various porosities can be calculated from the specific $\mathrm{Hg}$-volume, $v_{\mathrm{Hg}}$, for example:

$$
\varepsilon_{x t a l}(H g)=\frac{v_{H g}}{v_{H g}+\frac{1}{\rho_{x t a l}}}
$$

as the total porosity from MIP. Using $\rho_{\text {skel }}$ in Equation (3) yields the accessible porosity $\varepsilon_{\text {skel }}(\mathrm{Hg})$, where closed pores are excluded. With $\rho_{a p p}$, only the Hg-accessible (apparent) porosity $\varepsilon_{a p p}(\mathrm{Hg})$ is considered as shown in Figure 5(c4). The difference between $\varepsilon_{\text {skel }}$ $(\mathrm{Hg})$ and $\varepsilon_{\text {app }}(\mathrm{Hg})$ results in the amount of pore volume accessible for helium but not for mercury. Inaccessible regions for $\mathrm{Hg}$ could also be due to too small pore entries of $<3.7 \mathrm{~nm}$ or due to pressure-induced changes in the microstructure, e.g., changes in the elastic CBD. All calculated porosities from MIP are summarized, in comparison to the total porosity $\varepsilon$ determined by gauge measurements, in Table 2 . In addition, the specific pore surface area $\sigma_{\text {pore }}$ was determined from PSD results. 
Table 2. Results from MIP and comparison of calculated porosity with total porosity $\varepsilon$ from gauge measurement. The results from MIP are calculated with the different densities $\rho_{x t a l}, \rho_{\text {skel }}$ and $\rho_{\text {app }}$. Assuming a conical model for the pore shape, the specific pore surface area, $\sigma_{\text {pore }}$, can be calculated from PSD.

\begin{tabular}{ccccc}
\hline \multicolumn{4}{c}{ Porosity (\%) Derived by Gauge and MIP Measurements } & MIP $\sigma_{\text {pore }}\left(\mathbf{m}^{\mathbf{2}} \mathbf{g}^{-\mathbf{1}}\right)$ \\
\hline$\varepsilon$ & $\varepsilon_{\text {xtal }}(\mathbf{H g})$ & $\varepsilon_{\text {skel }}(\mathbf{H g})$ & $\varepsilon_{\text {app }}(\mathbf{H g})$ & \\
\hline 44 & 37.8 & 36.9 & 34.4 & 1.3 \\
\hline 39 & 35.9 & 35.2 & 33.2 & 1.2 \\
\hline 30 & 28.2 & 27.5 & 26.1 & 1.5 \\
\hline 28 & 28.1 & 27.4 & 26.4 & 1.7 \\
\hline 26 & 23.2 & 22.6 & 22.1 & 1.6 \\
\hline 18 & 17.2 & 16.8 & 16.3 & 2.1 \\
\hline
\end{tabular}

The total porosity derived by gauge measurements tends to be higher than derived by MIP. The main reason is the inaccuracy of gauge measurements indicated in Section 3.1. Electrodes with an $\varepsilon$ of $30 \%$ and the related reference electrodes with an $\varepsilon$ of $28 \%$ confirm this statement, since there is only an insignificant difference between the $\varepsilon_{x t a l}(H g)$ of these samples. Furthermore, a gauge measurement overestimates the thickness of an electrode since only the thickest position of the electrode determines the result. This effect is amplified by structural heterogeneities of the samples. Thus, the largest difference between $\varepsilon$ and $\varepsilon_{x t a l}$ $(\mathrm{Hg})$ could be identified for uncalendered electrodes. In summary, to compare electrode microstructures, the porosity derived by MIP should be preferred to the porosity derived by gauge measurements.

The difference between the accessible porosities $\varepsilon_{\text {skel }}(\mathrm{Hg})$ and $\varepsilon_{\text {app }}(\mathrm{Hg})$ decreases from 2.5 (for $\varepsilon=44 \%$ ) to 0.5 (for $\varepsilon=18 \%$ ) percentage points. Since the pore shape changes with calendering, more pores are accessible for Hg-intrusion at lower electrode porosities. Another explanation is that the strong calendered electrodes are less compressible and, thus, more stable against the high intrusion pressure, which results in a measured porosity closer to the true electrode porosity. For applications, such as LIBs, $\varepsilon_{a p p}(H g)$ could have more relevance in terms of electrochemical performance than $\varepsilon_{\text {skel }}(\mathrm{Hg})$ since pore spaces with small entries of $<3.7 \mathrm{~nm}$, still accessible by He-gas, could be electrochemically inactive or cause high overpotentials due to the hindered Li-ion kinetics, especially at higher applied current densities. Further insights into microporosity could be gained by $\mathrm{N}_{2}$-physisorption.

As a result of Figure 5, the change in pore shape and the increase in the pores with a size $<100 \mathrm{~nm}$ for lower electrode porosity should lead to a change in the specific pore surface area, $\sigma_{\text {pore }}$. In Table 2, an increase in $\sigma_{\text {pore }}$ from $1.3(\varepsilon=44 \%)$ to $2.1 \mathrm{~m}^{2} \mathrm{~g}^{-1}(\varepsilon=18 \%)$ can be identified, thus confirming the previous findings. Although the pore structure of a composite electrode is usually a mixture of different pore shapes, a conical pore shape model was applied to calculate $\sigma_{\text {pore }}$ for all electrode porosities, because this shape allows the best description of the hysteresis of the Hg-intrusion and extrusion data in Figure 5a. Measurement of the specific surface area independent of the pore shape can be achieved by $\mathrm{N}_{2}$-physisorption, which can be incorporated into the evaluation of the strengths and limitations of the chosen pore shape model in the MIP results.

Despite the detailed insights into the electrode microstructure and porosity from MIP experiments, a correct interpretation of the results and deviations is crucial. The measurement principle of MIP, where $\mathrm{Hg}$ in the capillary forms together with the metal sleeve around the dilatometer a plate capacitor and the intruded $\mathrm{Hg}$-volume is proportional to the change in capacitance, is accurate up to $\pm 0.05 \mathrm{~mm}^{3}$. But further variance regarding $V_{\mathrm{Hg}}$, the filling volume of $\mathrm{Hg}$ in the dilatometer, and changes in temperature can result in a realistic accuracy of $\pm 2 \mathrm{~mm}^{3}$ for the determined porosity and up to $\pm 5 \mathrm{~mm}^{3}$ for the density calculation (values given by device distributor). With $V_{\mathrm{Hg}}$ ranging between 87 and $260 \mathrm{~mm}^{3}$ for lowest and highest electrode porosity, respectively, a relative error of $1-6 \%$ 
has to be considered. As for all analytical techniques in this study, the sample preparation can influence the accuracy of the results (e.g., cutting the electrode sheet into samples).

In addition, the use of an aluminum foil as a typical cathode electrode current collector [44] can lead to additional inaccuracies since $\mathrm{Al}$ and $\mathrm{Hg}$ can form an alloy [45]. However, this barely influences the results as the native oxide layer of $\mathrm{Al}$ prevents a reaction with $\mathrm{Hg}$ before and during the MIP measurement [45], which was confirmed by a baseline measurement of the pristine aluminum current collector. With complex systems, such as composite electrodes, a constant contact angle of $140^{\circ}$ between $\mathrm{Hg}$ and the electrode materials is considered as approximation.

When comparing the PSD from MIP with results from other methods (e.g., SEM or $\mathrm{N}_{2}$-physisorption) the definition of the pore size has to be considered, since MIP measures the pore entries that are of the same size as the pore bodies (e.g., cylindrical pores) or smaller (e.g., spherical pores). Furthermore, the speed of the pressure increase/decrease can shift the pore size determination (faster $=$ shift to smaller pore sizes). Structural heterogeneities (see Hg-entrapment) and the densification of the electrode surface, described by the CLSM results, amplifies the pore-blocking effect and shifts the PSD results to smaller pore sizes [46].

Since nearly all described effects influencing the results of MIP are similar for electrodes with the same composition, the comparison of different electrode porosities is reasonable. Furthermore, by comprehending the factors that influence PSD changes and comparing the results of MIP with other methods, such as SEM cross-sections, changes in the electrode manufacturing process can also be understood and analyzed.

Overall, MIP measurements have a higher accuracy and reproducibility for porosity determination than gauge measurements. In addition, insights into different porosities (total, accessible), pore shape, structural homogeneity, and specific pore surface area can be gained and result in a comprehensive overview of the electrode microstructure. Measuring the pore throats instead of pore bodies with MIP can be beneficial to understand ionic transport within an electrolyte, as ion mobility is limited by the narrowest passage on a pathway through the electrode pore network. Therefore, MIP is considered to be a major method for characterizing LIB composite electrodes.

Considering $\mathrm{N}_{2}$-physisorption, information about micro- $(<2 \mathrm{~nm})$, meso- $(2-50 \mathrm{~nm})$, small macropores $(>50 \mathrm{~nm})$ and the BET specific surface area, $\sigma_{B E T}$, can be gained, which can support the correct interpretation of the MIP results.

The linear isotherms of the $\mathrm{N}_{2}$-adsorption experiments are shown in Figure 6a (type II isotherm [14]). As determined by MIP, the specific inner surface area of the electrodes increased for lower porosity, which was attributed to cracking of secondary AM particles during calendering. Fitting of the linear region of the isotherms with the BET model resulted in a linear trend with regard to increasing $\sigma_{B E T}$ at reduced total electrode porosities as shown in Figure $6 \mathrm{~b}$. The specific surface area doubles from uncalendered electrodes $(44 \%)$ to highly densified electrodes (18\% porosity), which can be used as indicators for the quantification of the extent of particle cracking as a consequence of extensive calendering.

Due to the presence of micropores, the quantitative validity of the BET model is limited, as the processes of micropore filling and monolayer-multilayer adsorption might interfere $[14,47]$. Therefore, the results of the BET model represent an apparent specific surface area. From the $t$-plot (Figure S2), a micropore surface area of $\approx 0.3 \mathrm{~m}^{2} \mathrm{~g}^{-1}$ was found for all investigated electrode porosities. With a constant micropore surface area, the comparison of the BET surface areas remains valid. In comparison to the specific pore surface area from MIP, MIP showed approximately twice the values of $\mathrm{N}_{2}$-physisorption (Table 2 compared to Figure $6 \mathrm{~b}$ ). One reason is the possible shift in the PSD to smaller values in the MIP measurement, which results in a higher amount of smaller pores and a higher surface area. Another reason lies in the use of different models of the two methods to calculate the specific surface area. The BET model based on the specific monolayer capacity of the adsorbent in the electrode and $\sigma_{\text {pore }}$ from MIP simplifies the pore network to geometric shapes (here: conical). The latter model was also affected by changes in 
the pore shape due to the calendering of the electrodes. Therefore, $\sigma_{B E T}$ calculated from $\mathrm{N}_{2}$-physisorption should be used to describe the structure of the porous electrodes and to calculate the tortuosity (quadratic correlation between surface area and tortuosity) based on the model of Carniglia [16].
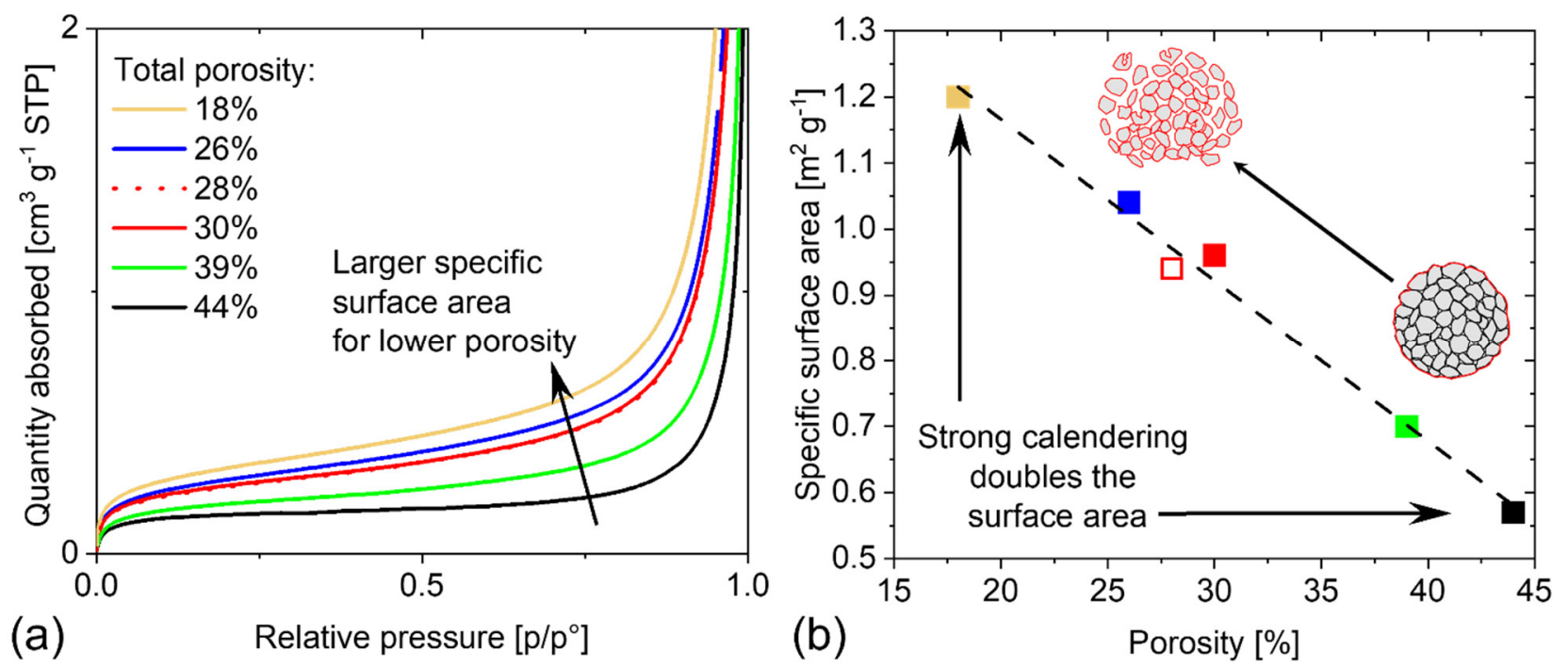

(a)

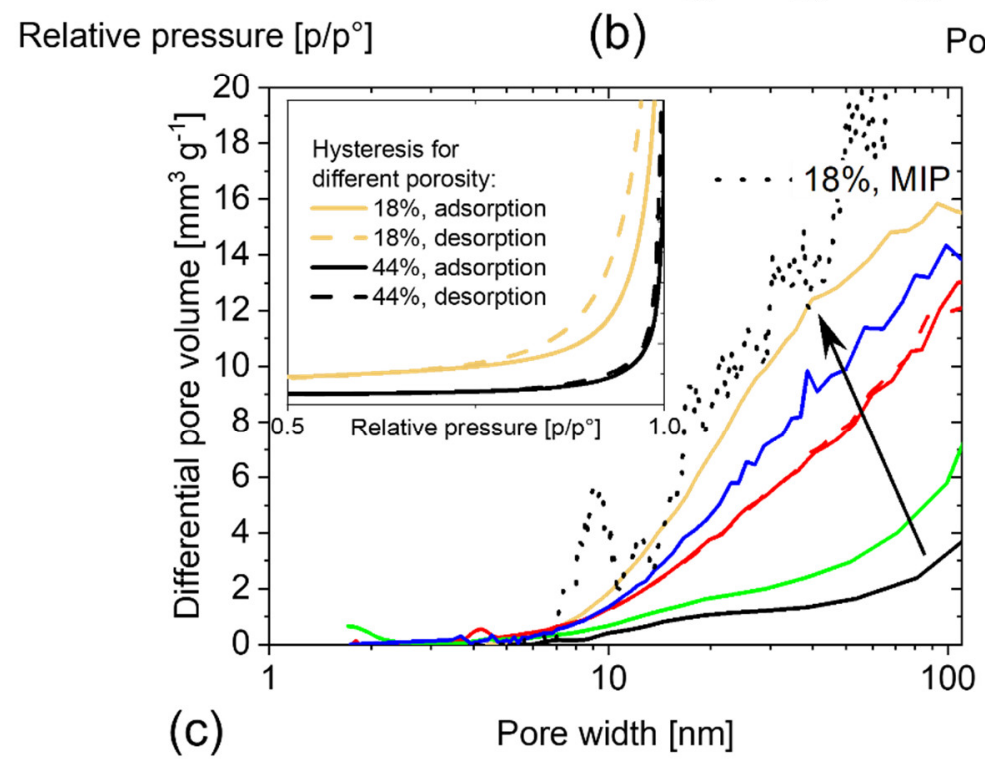

Figure 6. $\mathrm{N}_{2}$-physisorption: (a) linear adsorption isotherms for different porosities; increase of the specific surface areas with lower porosity; (b) specific surface area $\sigma_{\mathrm{BET}}$ using the BET method in relation to electrode porosity in the relative pressure range $\left(\mathrm{p} / \mathrm{p}^{\circ}\right)$ 0.05-0.15 (BET constant $\left.\mathrm{C}: \approx 70-100\right)$. Linear increase in $\sigma_{B E T}$ with lower porosity; (c) PSD calculated with the BJH method of the desorption branch of the isotherm. There was a larger hysteresis (inserted graph) for lower porosity, which resulted in more mesopores. PSD from the MIP of an electrode with $18 \%$ porosity is depicted by the dotted line and shows the same trend as the PSD from the physisorption experiment.

A change in the specific surface area can have a significant effect on the LIB performance and cycle life [48]. Cracking of AM particles results in an increased active specific surface area, which, however, can ultimately lead to enhanced detrimental side reactions between the AM surface and electrolyte [49].

Looking at the hysteresis of the isotherm (Figure 6c, inserted graph, type H3 [14]), mesopores were present in the calendered electrode, while they were absent in the uncalendered electrode showing no AM particle cracking or densification of the CBD. The shape of the hysteresis indicates the presence of slit-shaped pores, since the desorption branch was shallow and parallel to the adsorption branch over a wide pressure range [50]. As with the MIP, the PSD showed an increasing pore volume below a $100 \mathrm{~nm}$ pore size for low porosity 
electrodes. The shape of the PSD curves was comparable to the MIP experiments in the respective pore size range (Figure 6c; MIP shown as dotted line for $18 \%$ porosity). Therefore, it can be concluded that both methods are suitable for the analysis of LIB electrodes. At a pore size of $100 \mathrm{~nm}$, when the BJH model reaches its limit of validity, a slightly larger pore volume for MIP can be identified. The desorption branch of the isotherm mostly describes the size of pore throats, such as those in MIP, but $\mathrm{N}_{2}$-physisorption is less affected by pore shielding or comparable errors. In this case, the higher pore volume measured with MIP at pore sizes of approximately $100 \mathrm{~nm}$ could be explained by a shift in the PSD to smaller values, since larger pores are blocked from the intruding $\mathrm{Hg}$ by a barrier of pores with smaller pore diameters $\approx 100 \mathrm{~nm}$ as shown in Figure $5 \mathrm{c}$.

Quantifying the micropore volume is not possible with the BJH model but with a discrete Fourier transform calculation [14]. However, due to the high complexity of the pore network and its heterogeneity, there is no simple model to describe the whole pore structure ranging from micro- to macropores with different pore shapes.

Considering the real electrode pore system in an LIB filled with electrolytes, micropore volume may not be crucial for a good electrochemical performance. Markoulidis et al. showed the influence of micropores on the performance of electrochemical double-layer capacitors [51]. Therein, it was stated that below a $1.8 \mathrm{~nm}$ pore size, the solvated Li-ions start to change their coordination in a standard electrolyte (1 M LiPF6 in ethylene carbonate (EC) and ethyl methyl carbonate (EMC), EC:EMC 50:50 wt\%). In addition, $\mathrm{PF}_{6}$ ions were desolvated in micropores smaller than $1.4 \mathrm{~nm}$ and kinetics for the ion transport slows down. Thus, especially for fast charging/discharging in LIBs, micropores could be inactive in terms of Li-ion transportation. Considering other battery systems, such as solid-state batteries, micropores and small mesopores can have a detrimental effect, because they hinder Li-ion mobility due to the nonconductive gaps between the solid electrolyte and/or AM particles.

The accuracy of $\mathrm{N}_{2}$-physisorption was illustrated by the electrode with $30 \%$ total porosity and the reference electrode $(\varepsilon=28 \%)$. No variance between the two porosities could be identified for the linear isotherm and the PSD. The difference in the two $\sigma_{B E T}$ was $2 \%$. Considering the systematic error of the device (e.g., the accuracy of pressure reading) and the limitations of the experimental setup (e.g., a limited sample space in tube), a realistic inaccuracy for the adsorbed quantity and the surface area was up to $5-10 \%$. Therefore, the deviation for the BET results ( $\varepsilon=30 \%$ compared to $\varepsilon=28 \%$ ) was negligible and the micropore volume was in the range of the variance of the pressure reading. For samples with a small specific surface area, changing the analysis gas to krypton could lead to more accurate results due to the higher sensitivity [14]. To keep the electrode structure unchanged during the sample preparation, the degassing temperature was reduced to $120{ }^{\circ} \mathrm{C}$ compared to inorganic powder samples (approximately $200{ }^{\circ} \mathrm{C}$ ) but remaining contaminations are possible, e.g., clogged micropores.

Despite these limitations, when measuring electrodes with a small specific surface area compared to powder samples, $\mathrm{N}_{2}$-physisorption provides a more accurate result for a specific surface area than MIP measurements and confirms the PSD results of MIP in the pore size range of mesopores and small macropores $(<100 \mathrm{~nm})$. By comparing these two methods, a correct interpretation of the MIP outcome is possible considering measurement artifacts such as pore shielding. The accuracy of both methods depends on the porosity of the investigated electrodes, with low porosity favoring $\mathrm{N}_{2}$-physisorption (especially for determination of $\sigma_{B E T}$ ) and high porosity favoring MIP (especially determination of the pore volume). However, despite the drawbacks, a comprehensive overview of the electrode microstructure can only be gained by MIP measurements.

\subsection{Focused Ion Beam/Scanning Electron Microscopy Tomography}

The results of the previous methods can be verified using FIB/SEM tomography combined with a digital 3D model applying the GeoDict2020 software to gain further insights into the electrode microstructure. For this purpose, the electrode with the lowest 
porosity $(18 \%)$ was investigated. Highly densified electrodes are rarely investigated in the literature, even though the low porosities are required to achieve high energy densities of the battery cell. Intense calendering results in extensive changes to AM particles in terms of cracking and distortion, whereby a 3D instead of 2D visualization is beneficial for a comprehensive understanding of microstructural properties.

Figure 7 shows a FIB-prepared cross-section with its microstructural features. It verifies the results regarding the presence of closed pores in AM particles, AM particle cracking predominantly at the electrode surface, and that most of the space between the AM particles was filled with CBD. The cracking of large AM particles (e.g., at the left border of the FIB cross-section) could result in theoretical access (e.g., He-gas) to originally closed pores. Pore sizes from small mesopores inside the CBD to macropores in the lower parts of the electrode could be detected. The larger macropore depicted in Figure 7 illustrates the limitations of the previous methods. With MIP, the actual macropore would be measured at smaller pore sizes due to the small pore entry. For $\mathrm{N}_{2}$-physisorption, the pore size was above the detection limit, and in an embedded cross-section, the epoxy resin would reduce the contrast between $\mathrm{CBD}$ and pore.

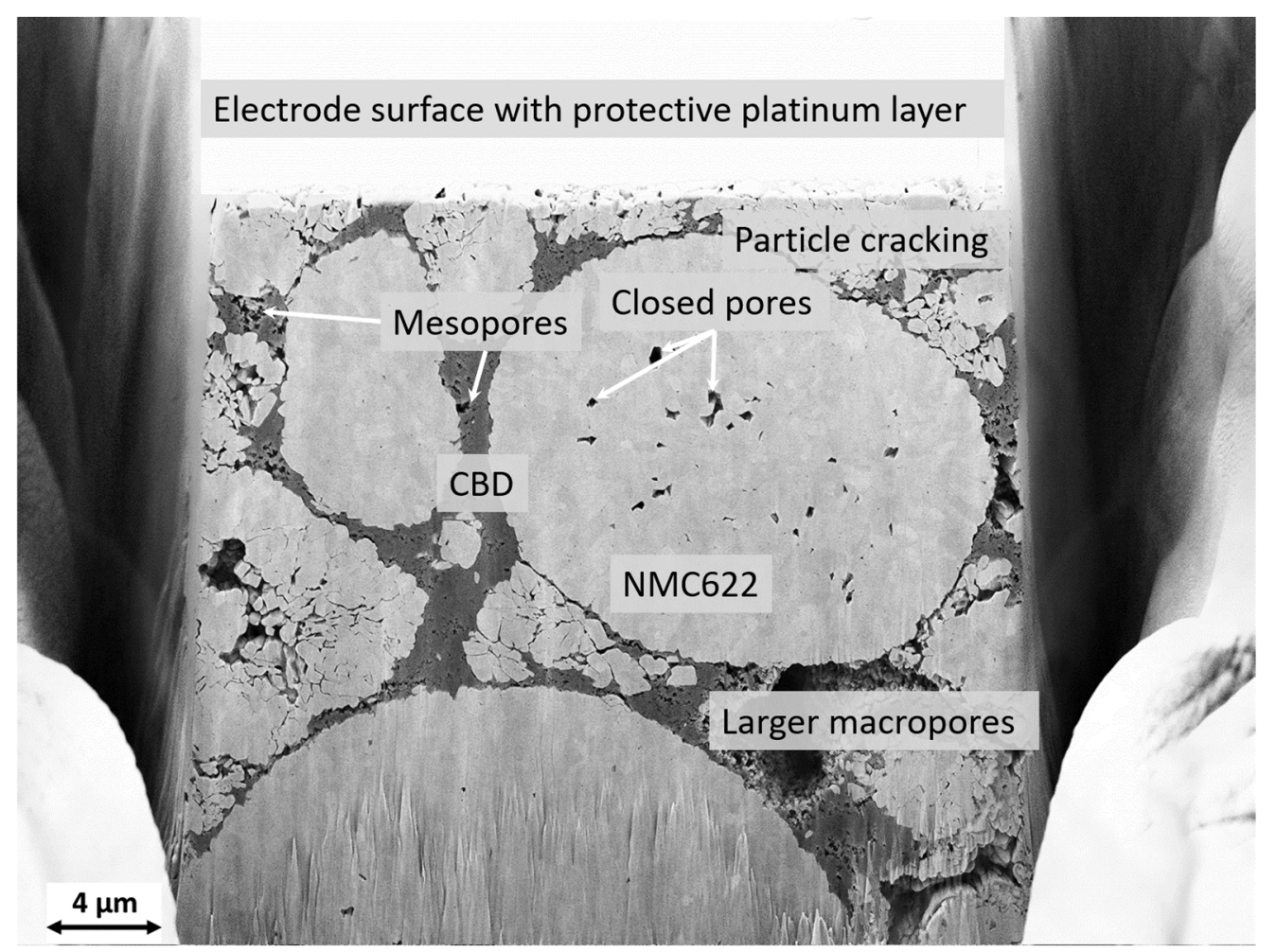

Figure 7. FIB/SEM tomography of a positive electrode with a porosity $<20 \%$. All significant microstructural features are marked.

To finalize the results of the previous methods and to create a 3D model using tomography in the next step, the focus of the FIB/SEM experiments was on the microstructure and porosity of the electrode. Therefore, the measurement parameters were optimized for the visualization of the AM, the AM particle cracking, and the closed pores within the AM. In this work, an FIB current of 2 nA was used for visualizing a larger tomography volume, and the CBD was simulated in the void space between AM particles for 3D reconstruction.

To resolve the CBD structure and the according mesopores, the required FIB preparation parameters led to a tradeoff between a longer measurement time and smaller tomography volume. Only using low FIB currents (e.g., 20 pA [27]) for the cross-section preparation of CBD could preserve the according structure. Otherwise, melting effects occur and result in preparational structural changes such as clogging of pores within the CBD. Therefore, in literature FIB/SEM tomography is typically combined with simulations [27,52,53]. 
Comparing the structure of the electrode in this study with the results in the literature, significantly higher electrode total porosities, where $\varepsilon$ was at least $31 \%$ [36] and often higher $[27,52,53]$ than in this study $(\varepsilon=18 \%)$, have to be considered. Stronger calendering as applied herein resulted in more AM particle cracking and in a different, more densified CBD structure. The conductive agent-to-binder ratio was set herein to 2:3, whereas in the literature, it was often 1:1, which changes the binder-to-surface area ratio and, therefore, the CBD structure.

Since there are also electrode materials behind the sectional plane visible in Figure 7 , an automatized discrimination of the phases (i.e., AM, CBD, pores) is challenging. To transfer the tomography data of the electrode to a 3D model, a high contrast for the microstructural features (AM, particle cracking, and closed pores) within the sectional plane was used (Figure 8b).
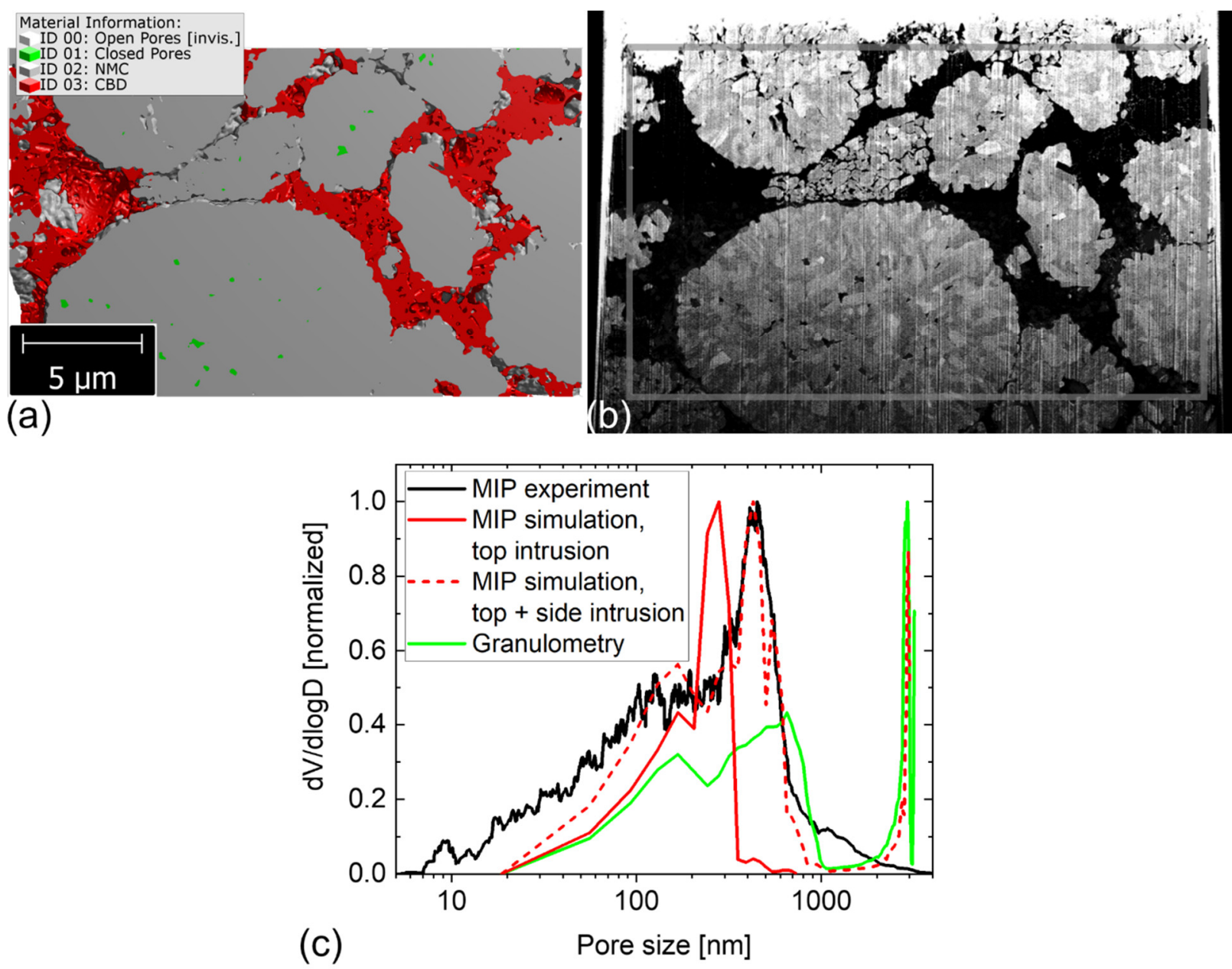

Figure 8. FIB/SEM tomography of a positive electrode with a porosity $<20 \%$. Transfer of the SEM image in (b) to a digital model in (a). (c) Shows the results for MIP of the experiment described in Section 3.4. and of the digital model plus the granulometry from the latter. In the model, the mercury intruded either from all sides (except from the bottom) or only from the top.

A digital 3D model can be created based on the FIB-prepared cross-sectional micrographs applying the GeoDict2020 software. The results are shown in Figure 8, with an example of an FIB-prepared cross-section and the same position in the digital model. The size of the extracted volume (Figure 8a and Figure S3) was $24.2 \times 14.7 \times 17.9 \mu \mathrm{m}$ (width $\times$ height $\times$ depth) with a voxel edge length of $37.2 \mathrm{~nm}$ in each direction. The statistical digital twin enabled a better in-depth understanding of the microstructure and the simulation or calculation of the electrochemical and mechanical electrode properties. 
The CBD was simulated on basis of the PSD from the MIP experiment $(\varepsilon=18 \%)$ (see Figures 5 and $8 \mathrm{c}$ ) and the ratio of the volumetric amount of AM to CBD in the electrode recipe (see Table 1).

As the binder also covers the AM in the real composite electrodes, the volume of the $\mathrm{CBD}$ in the model could be overestimated. Other research groups adjusted the CBD structure to fit Li-ion or electronic conductivity measurements [36,37,53].

In the literature, the porosity of CBD varies from $47 \%$ (nanoporosity [53]) via $50 \%$ [36] to $58 \%$ [27]. The porosity of the digitally created CBD in this study was $50.2 \%$ with a minimal pore diameter of $37.2 \mathrm{~nm}$, limited by the voxel length. When simulating CBD, the distribution in the electrode could be random, contact, or surface oriented [36], and the connections within the CBD in blocking, fully open, and partially open configurations for Li-ion diffusion [37]. In this study, the distribution of CBD was controlled by decreasing the surface energy and considering an open configuration for the channels within the CBD.

Since simulating the CBD cannot be achieved by applying a singular correct model, the best model for the respective application has to be identified, fitting the measurements of the microstructure or the electrochemical experiments (herein MIP).

To compare the porosity and PSD within the digital model with the previous results, GeoDict can perform a simulated MIP or granulometry experiment. The processes of the MIP were simulated as in the experiment with $\mathrm{Hg}$ intruding from all sides except the electrode bottom, close to the non-porous current collector, or only from the surface of the electrode considering larger electrode areas as in commercial applications $[38,39]$. The simulated CBD determined the PSD (see Figure 8c) in the significant range from 19 to $1000 \mathrm{~nm}$. Larger pores between AM secondary particles that were not filled with CBD had only a minor influence on the results of the MIP simulation in this pore size region. Thus, the relevance of the CBD and of the correct CBD simulation increase with lower electrode porosity (here $18 \%$ ).

Since a few larger pores were created by the simulation, differences in the results can be identified depending on how the PSD was determined. If $\mathrm{Hg}$ was only allowed to intrude from the sample surface, as in most of the experiments, the pore volume of larger pores $(>1 \mu \mathrm{m})$ was filled through smaller pore entries $(<1 \mu \mathrm{m})$ at the dense electrode surface as shown in Figure 5c. If $\mathrm{Hg}$ could intrude from all sides except from the current collector side or if granulometry was used, the larger pores were also depicted by modeling of the PSD. The MIP simulation and MIP experiment both had a D50 of the pores in the range of 200-260 nm. Using granulometry instead of MIP resulted in a shift of the PSD to higher values. This suggests that the pores had a smaller entrance than diameter or even a complete pore shielding effect occurred. In the MIP experiments, a conical model of the pores was used to calculate the PSD. Regardless of the model, the observation considering larger pores isolated within the highly densified electrode, which are only measured at higher pressures in the MIP experiment, is confirmed in Figure 7.

The digital model of the electrode showed a lower total porosity than in the gauge measurement $(16.1 \%$ instead of $18 \%)$ and, therefore, resulted in a slightly higher electrode density of $3.72 \mathrm{~g} \mathrm{~cm}^{-3}$ compared to $3.65 \mathrm{~g} \mathrm{~cm}^{-3}$. In addition, $\varepsilon_{\text {inacc }}$ had a value of $0.5 \%$, more than four times smaller in the model compared to the value determined with Hepycnometry. Therefore, $\varepsilon_{a c c}$ was also slightly smaller compared to the MIP experiments. However, the localization, which was not possible to detect with He-pycnometry, and quantification of closed pores (marked green in Figures 8a and S3) within the AM is an advantage of the 3D reconstruction, as it is important for simulation of ionic transport in AM secondary particles and their mechanical properties, which is often neglected in the literature [54]. The closed pores were distributed within the AM secondary particles and not only in the particle center as assumed from the results of the embedded cross-sections.

One reason for the difference in total porosity of up to 2 percentage points is the lower limit of the pore size in the model. The batch size in the simulation was chosen to be the voxel length of $37.2 \mathrm{~nm}$. Therefore, in the MIP simulation, pore throat diameters smaller than $18.6 \mathrm{~nm}$ were not covered, while the experiment covered pore throats down 
to $3.7 \mathrm{~nm}$. For the strongest calendered electrode, $3.7 \%$ of $\varepsilon_{\text {acc }}$ were in this range in the MIP experiment. Hence, 0.6 percentage points must be added to $\varepsilon_{a c c}$ from the simulation (now $16.2 \%$ ) to be comparable to the experiment.

Since the depth of the prepared cross-section for FIB/SEM tomography was not covering the overall electrode thickness, the extracted electrode section for the simulation was from the top third (close to the surface) of the electrode. To some extent, more particle cracking was observed at this surface-near position compared to parts closer to the current collector. This resulted in a slightly denser electrode and a lower total porosity of the investigated electrode section. This effect could be amplified by a heterogenous distribution of the CBD within the electrode, as only the ratio of AM to CBD from the electrode recipe was applied in the model. Binder migration during the drying process or a segregation during calendering could lead to higher and lower amounts of CBD at some positions in the electrode [42,55]. Contradicting this, embedded SEM cross-sections in Figures 4 and S1 suggest a homogeneous distribution of all components.

The major difference between the experiments and the digital model was in the amount of $\varepsilon_{\text {inacc }}$, which was more than four times smaller in the model. Here, the absolute accuracy and the made assumptions (e.g., $\rho_{\text {theo }}$ of AM is $\rho_{x t a l}$ ) of all the experimental methods have to be considered, as they can lead to large relative errors for the small values of $\varepsilon_{\text {inacc }}$. A similar effect could originate from the comparatively small electrode, thus sample section investigated by FIB/SEM tomography. More particle cracking of secondary particles resulted in more access points to originally closed pores in AM in the model. As stated, the CBD model did not include nanoporosity with diameters smaller than $37.2 \mathrm{~nm}$ and no closed pores associated with the CBD.

For the segmentation of the FIB/SEM 3D image data, a non-local means filter was applied besides others, and the threshold for segmentation between active material and pore was chosen manually. These two factors might lead to small errors during segmentation, especially regarding small pores and cracks in the active material. It must be assumed that during the segmentation process, information regarding small pores and cracks in the active material are lost and, therefore, that the percentage of closed pores in the structure is underestimated.

Overall, the FIB/SEM tomography is a comprehensive complementary method to the previous methods that improves the understanding of the electrode microstructure and allows for the evaluation of the different porosity measurements. The modeling of the CBD in particular shows how important the correct representation of the inactive components is and where mistakes can be made when considering just porosity from experimental data.

\section{Conclusions and Outlook}

Positive electrodes with porosities ranging from $18 \%$ to $44 \%$ were prepared and analyzed regarding their porosity and pore size distribution. Each measuring technique showed its advantages and different insights into the microstructure of the electrodes, whereby possible inaccuracies of the methods were discussed and compared in detail. Therefore, variations in the total porosity should be specified as integer values, as the significance of the decimal place is considered unreasonable for composite electrodes. Moreover, the entire pore size range of composite electrodes cannot be covered by applying only a single method. Only a combination of the methods enabled a complete characterization of the electrode microstructure. For the complete range of pore sizes (except micropores) in LIBs, MIP provides the best overview and reproducibility, and due to the large number of samples, is representative for electrode production. However, closed pores cannot be measured directly and the electrode densities, measured with a gauge, He-pycnometry, and X-ray diffraction, are necessary for the correct interpretation of MIP results. A comparison with $\mathrm{N}_{2}$-physisorption enables the determination and exclusion of deviations induced by effects such as pore-blocking. With the technique access to micropores, gas-based methods are particularly relevant for electrodes that are highly densified and have a major fraction of micro- and mesopores or other battery systems such as solid-state batteries. A combination 
of FIB/SEM tomography and 3D modeling of the electrode provides the most descriptive overview for all types of pores and the opportunity for a direct transfer to other topics of interest, such as Li-ion mobility, hence, the electrochemical performance of the electrodes in LIBs. Here, an unresolved nanoporosity of the CBD with a given tortuosity can be respected in electrochemical GeoDict [56]. Above all, the importance of the correct representation of the CBD becomes clear.

The effects of different porosities on the electrochemical performance of LIBs and lithium metal batteries are currently under investigation and will be published shortly. For hands-on research, it is particularly relevant how the pore structure within the electrodes behaves in combination with an electrolyte and how it changes as the cells cycle. In any case, as a basis for further investigations of electrode properties, an in-depth understanding of the electrode microstructure and porosity is essential.

Supplementary Materials: The following are available online at https:/ /www.mdpi.com/article/10 .3390 /batteries7040070/s1, Figure S1: Additional SEM cross-sectional images of embedded electrodes, Figure S2: $t$-plots from $\mathrm{N}_{2}$-physisorption, Figure S3: 3D model of the FIB/SEM tomography.

Author Contributions: Conceptualization, methodology, investigation, writing-original draft preparation, T.B.; simulation, model building and validation, M.F. and C.W.; supervision, writingreview and editing, M.W. and M.B. All authors have read and agreed to the published version of the manuscript.

Funding: This research was funded by Federal Ministry of Education and Research: 03XP0109A; Federal Ministry for Economic Affairs and Energy: 03ETE018B; Federal Ministry of Education and Research: FoFeBat.

Institutional Review Board Statement: Not applicable.

Informed Consent Statement: Not applicable.

Acknowledgments: The authors would like to thank the German Federal Ministry of Education and Research (BMBF) for financial support within the "BCT-Battery Cell Technology" project (03XP0109A) and the Research Fab Battery Cells (FoFeBat). The authors of Math2Market GmbH would like to thank the German Federal Ministry of Economic Affairs and Energy for financial support within the "structure" project (03ETE018B).

Conflicts of Interest: The authors declare no conflict of interest.

\section{Abbreviations}

$\begin{array}{ll}\text { Abbreviation } & \text { Name } \\ \text { AM } & \text { Active material } \\ \text { BET } & \text { Brunauer-Emmett-Teller } \\ \text { BJH } & \text { Barrett, Joyner, and Halenda } \\ \text { CB } & \text { Carbon black } \\ \text { CBD } & \text { Carbon and binder domain } \\ \text { CLSM } & \text { Confocal laser scanning microscope } \\ \text { EC } & \text { Ethylene carbonate } \\ \text { EMC } & \text { Ethyl methyl carbonate } \\ \text { FIB } & \text { Focus ion beam } \\ \text { IM } & \text { Inactive material } \\ \text { LIB } & \text { Lithium-ion batteries } \\ \text { MIP } & \text { Mercury intrusion porosimetry } \\ \mathrm{N}_{2} & \text { Nitrogen gas } \\ \text { NMC622 } & \text { LiNi }{ }_{0.6} \text { Mn }_{0.2} \text { Co }_{0.2} \mathrm{O}_{2} \\ \text { NMP } & \text { N-Methyl-2-pyrrolidone } \\ \text { PSD } & \text { Pore size distribution } \\ \text { PVdF } & \text { Polyvinylidene difluoride } \\ \text { SEM } & \text { Scanning electron microscopy }\end{array}$




$\begin{array}{lll}\text { Symbol } & \text { Name } & \text { Unit } \\ m_{\text {sample }} & \text { sample mass } & \mathrm{g} \\ D & \text { pore diameter } & \mathrm{nm} \\ V_{\text {bulk }}(\mathrm{Hg}) & \text { bulk sample volume from MIP after Hg wetting } & \mathrm{mm}^{3} \\ V_{H g} & \text { intrude Hg-volume } & \mathrm{mm}^{3} \\ v_{H g} & \text { specific intruded Hg-volume } & \mathrm{mm}^{3} \mathrm{~g}^{-1} \\ \rho_{\text {bulk }} & \text { bulk density of coated film } & \mathrm{g} \mathrm{cm}^{-3} \\ \rho_{\text {theo }} & \text { theoretical density of solid compounds of coated film, } & \mathrm{g} \mathrm{cm}^{-3} \\ \rho_{\text {skel }} & \text { in this study } \rho_{\text {xtal }} & \mathrm{g} \mathrm{cm}^{-3} \\ \rho_{\text {xtal }} & \text { skeletal density from gas pycnometry } & \mathrm{g} \mathrm{cm}^{-3} \\ \rho_{\text {bulk }}(\mathrm{Hg}) & \text { crystallographic density } & \mathrm{g} \mathrm{cm}^{-3} \\ \rho_{\text {app }} & \text { bulk density, sample volume from MIP } & \mathrm{g} \mathrm{cm}^{-3} \\ \varepsilon & \text { apparent density from MIP, } V_{\text {bulk }}(\mathrm{Hg}) \text { corrected by } V_{\mathrm{Hg}} & - \\ \varepsilon_{\text {acc }} & \text { total porosity } & - \\ \varepsilon_{\text {inacc }} & \text { accessible porosity } & - \\ \varepsilon_{x t a l}(\mathrm{Hg}) & \text { inaccessible porosity, closed pores } & - \\ \varepsilon_{\text {skel }}(\mathrm{Hg}) & \text { total porosity, pore volume from MIP } & \text { accessible porosity, pore volume from MIP } \\ \varepsilon_{\text {app }}(\mathrm{Hg}) & \text { apparent porosity from MIP, for Hg accessible porosity } & - \\ \sigma_{\text {pore }} & \text { specific pore surface area from MIP } & - \\ \sigma_{\text {BET }} & \text { specific surface area from N2-physisorption, BET model } & \mathrm{m}^{2} \mathrm{~g}^{-1} \\ \end{array}$

\section{References}

1. Placke, T.; Kloepsch, R.; Dühnen, S.; Winter, M. Lithium ion, lithium metal, and alternative rechargeable battery technologies: The odyssey for high energy density. J. Solid State Electrochem. 2017, 21, 1939-1964. [CrossRef]

2. Winter, M.; Barnett, B.; Xu, K. Before Li ion batteries. Chem. Rev. 2018, 118, 11433-11456. [CrossRef]

3. Qi, X.; Blizanac, B.; DuPasquier, A.; Oljaca, M.; Li, J.; Winter, M. Understanding the influence of conductive carbon additives surface area on the rate performance of $\mathrm{LiFePO} 4$ cathodes for lithium ion batteries. Carbon 2013, 64, 334-340. [CrossRef]

4. Chen, Y.H.; Wang, C.W.; Zhang, X.; Sastry, A.M. Porous cathode optimization for lithium cells: Ionic and electronic conductivity, capacity, and selection of materials. J. Power Sources 2010, 195, 2851-2862. [CrossRef]

5. Forouzan, M.M.; Chao, C.-W.; Bustamante, D.; Mazzeo, B.A.; Wheeler, D.R. Experiment and simulation of the fabrication process of lithium-ion battery cathodes for determining microstructure and mechanical properties. J. Power Sources 2016, 312, 172-183. [CrossRef]

6. Schmidt, D.; Kamlah, M.; Knoblauch, V. Highly densified NCM-cathodes for high energy Li-ion batteries: Microstructural evolution during densification and its influence on the performance of the electrodes. J. Energy Storage 2018, 17, 213-223. [CrossRef]

7. Zheng, H.; Liu, G.; Song, X.; Ridgway, P.; Xun, S.; Battaglia, V.S. Cathode performance as a function of inactive material and void fractions. J. Electrochem. Soc. 2010, 157, A1060-A1066. [CrossRef]

8. Zheng, H.; Tan, L.; Liu, G.; Song, X.; Battaglia, V.S. Calendering effects on the physical and electrochemical properties of Li[Ni1/3Mn1/3Co1/3]O2 cathode. J. Power Sources 2012, 208, 52-57. [CrossRef]

9. Feigin, L.; Svergun, D.I. Structure Analysis by Small-Angle X-ray and Neutron Scattering; Plenum Press: New York, NY, USA, 1987; Volume 1.

10. Calo, J.; Hall, P. The application of small angle scattering techniques to porosity characterization in carbons. Carbon 2004, 42 , 1299-1304. [CrossRef]

11. Brunauer, S.; Emmett, P.H.; Teller, E. Adsorption of gases in multimolecular layers. J. Am. Chem. Soc. 1938, 60, 309-319. [CrossRef]

12. Barrett, E.P.; Joyner, L.G.; Halenda, P.P. The determination of pore volume and area distributions in porous substances. I. Computations from nitrogen isotherms. J. Am. Chem. Soc. 1951, 73, 373-380. [CrossRef]

13. Sing, K. The use of nitrogen adsorption for the characterisation of porous materials. Colloids Surf. A Physicochem. Eng. Asp. 2001, 187, 3-9. [CrossRef]

14. Thommes, M.; Kaneko, K.; Neimark, A.V.; Olivier, J.P.; Rodriguez-Reinoso, F.; Rouquerol, J.; Sing, K.S.W. Physisorption of gases, with special reference to the evaluation of surface area and pore size distribution (IUPAC Technical Report). Pure Appl. Chem. 2015, 87, 9-10. [CrossRef]

15. Washburn, E.W. Note on a method of determining the distribution of pore sizes in a porous material. Proc. Natl. Acad. Sci. USA 1921, 7, 115. [CrossRef] [PubMed]

16. Carniglia, S. Construction of the tortuosity factor from porosimetry. J. Catal. 1986, 102, 401-418. [CrossRef]

17. Froboese, L.; Titscher, P.; Westphal, B.; Haselrieder, W.; Kwade, A. Mercury intrusion for ion-and conversion-based battery electrodes-structure and diffusion coefficient determination. Mater. Charact. 2017, 133, 102-111. [CrossRef]

18. Novák, P.; Scheifele, W.; Winter, M.; Haas, O. Graphite electrodes with tailored porosity for rechargeable ion-transfer batteries. J. Power Sources 1997, 68, 267-270. [CrossRef] 
19. Ferg, E.; Loyson, P.; Rust, N. Porosity measurements of electrodes used in lead-acid batteries. J. Power Sources 2005, 141, 316-325. [CrossRef]

20. Volfkovich, Y.M.; Bagotzky, V. The method of standard porosimetry: 1. Principles and possibilities. J. Power Sources 1994, 48, 327-338. [CrossRef]

21. Volfkovich, Y.M.; Bagotzky, V.; Sosenkin, V.; Blinov, I. The standard contact porosimetry. Colloids Surf. A Physicochem. Eng. Asp. 2001, 187, 349-365. [CrossRef]

22. Etiemble, A.; Besnard, N.; Bonnin, A.; Adrien, J.; Douillard, T.; Tran-Van, P.; Gautier, L.; Badot, J.C.; Maire, E.; Lestriez, B. Multiscale morphological characterization of process induced heterogeneities in blended positive electrodes for lithium-ion batteries. J. Mater. Sci. 2016, 52, 3576-3596. [CrossRef]

23. Meyer, C.; Bockholt, H.; Haselrieder, W.; Kwade, A. Characterization of the calendering process for compaction of electrodes for lithium-ion batteries. J. Mater. Process. Technol. 2017, 249, 172-178. [CrossRef]

24. Almar, L.; Joos, J.; Weber, A.; Ivers-Tiffée, E. Microstructural feature analysis of commercial Li-ion battery cathodes by focused ion beam tomography. J. Power Sources 2019, 427, 1-14. [CrossRef]

25. Ender, M.; Joos, J.; Carraro, T.; Ivers-Tiffée, E. Quantitative Characterization of LiFePO4Cathodes Reconstructed by FIB/SEM Tomography. J. Electrochem. Soc. 2012, 159, A972-A980. [CrossRef]

26. Moroni, R.; Börner, M.; Zielke, L.; Schroeder, M.; Nowak, S.; Winter, M.; Manke, I.; Zengerle, R.; Thiele, S. Multi-Scale Correlative Tomography of a Li-Ion Battery Composite Cathode. Sci. Rep. 2016, 6, 30109. [CrossRef] [PubMed]

27. Vierrath, S.; Zielke, L.; Moroni, R.; Mondon, A.; Wheeler, D.R.; Zengerle, R.; Thiele, S. Morphology of nanoporous carbon-binder domains in Li-ion batteries-A FIB-SEM study. Electrochem. Commun. 2015, 60, 176-179. [CrossRef]

28. Lagadec, M.F.; Zahn, R.; Müller, S.; Wood, V. Topological and network analysis of lithium ion battery components: The importance of pore space connectivity for cell operation. Energy Environ. Sci. 2018, 11, 3194-3200. [CrossRef]

29. Landesfeind, J.; Ebner, M.; Eldiven, A.; Wood, V.; Gasteiger, H.A. Tortuosity of Battery Electrodes: Validation of ImpedanceDerived Values and Critical Comparison with 3D Tomography. J. Electrochem. Soc. 2018, 165, A469-A476. [CrossRef]

30. Rahe, C.; Kelly, S.T.; Rad, M.N.; Sauer, D.U.; Mayer, J.; Figgemeier, E. Nanoscale X-ray imaging of ageing in automotive lithium ion battery cells. J. Power Sources 2019, 433, 126631. [CrossRef]

31. Rajendra, T.; Mistry, A.N.; Patel, P.; Ausderau, L.J.; Xiao, X.; Mukherjee, P.P.; Nelson, G.J. Quantifying Transport, Geometrical, and Morphological Parameters in Li-Ion Cathode Phases Using X-ray Microtomography. ACS Appl. Mater. Interfaces 2019, 11, 19933-19942. [CrossRef] [PubMed]

32. Rucci, A.; Ngandjong, A.C.; Primo, E.N.; Maiza, M.; Franco, A.A. Tracking variabilities in the simulation of Lithium Ion Battery electrode fabrication and its impact on electrochemical performance. Electrochim. Acta 2019, 312, 168-178. [CrossRef]

33. Cunha, R.P.; Lombardo, T.; Primo, E.N.; Franco, A.A. Artificial Intelligence Investigation of NMC Cathode Manufacturing Parameters Interdependencies. Batter. Supercaps 2020, 3, 60-67. [CrossRef]

34. Vilchevskaya, E.; Sevostianov, I. Effect of pore shapes on the overall electrical conductivity of cathode material in Li-ion batteries. Int. J. Eng. Sci. 2020, 146, 103187. [CrossRef]

35. Landesfeind, J.; Eldiven, A.; Gasteiger, H.A. Influence of the Binder on Lithium Ion Battery Electrode Tortuosity and Performance. J. Electrochem. Soc. 2018, 165, A1122-A1128. [CrossRef]

36. Hein, S.; Danner, T.; Westhoff, D.; Prifling, B.; Scurtu, R.; Kremer, L.; Hoffmann, A.; Hilger, A.; Osenberg, M.; Manke, I. Influence of Conductive Additives and Binder on the Impedance of Lithium-Ion Battery Electrodes: Effect of Morphology. J. Electrochem. Soc. 2020, 167, 013546. [CrossRef]

37. Chouchane, M.; Primo, E.N.; Franco, A.A. Mesoscale Effects in the Extraction of the Solid-State Lithium Diffusion Coefficient Values of Battery Active Materials: Physical Insights from 3D Modeling. J. Phys. Chem. Lett. 2020, 11, 2775-2780. [CrossRef]

38. Ahrenholz, B.; Tölke, J.; Lehmann, P.; Peters, A.; Kaestner, A.; Krafczyk, M.; Durner, W. Prediction of capillary hysteresis in a porous material using lattice-Boltzmann methods and comparison to experimental data and a morphological pore network model. Adv. Water Resour. 2008, 31, 1151-1173. [CrossRef]

39. Hilpert, M.; Miller, C.T. Pore-morphology-based simulation of drainage in totally wetting porous media. Adv. Water Resour. 2001, 24, 243-255. [CrossRef]

40. Nguyen, H.G.T.; Horn, J.C.; Bleakney, M.; Siderius, D.W.; Espinal, L. Understanding material characteristics through signature traits from helium pycnometry. Langmuir 2019, 35, 2115-2122. [CrossRef] [PubMed]

41. Haselrieder, W.; Ivanov, S.; Christen, D.K.; Bockholt, H.; Kwade, A. Impact of the calendering process on the interfacial structure and the related electrochemical performance of secondary lithium-ion batteries. ECS Trans. 2013, 50, 59. [CrossRef]

42. Günther, T.; Schreiner, D.; Metkar, A.; Meyer, C.; Kwade, A.; Reinhart, G. Classification of Calendering-Induced Electrode Defects and Their Influence on Subsequent Processes of Lithium-Ion Battery Production. Energy Technol. 2020, 8, 1900026. [CrossRef]

43. Rigby, S.P.; Edler, K.J. The influence of mercury contact angle, surface tension, and retraction mechanism on the interpretation of mercury porosimetry data. J. Colloid Interface Sci. 2002, 250, 175-190. [CrossRef]

44. Krämer, E.; Passerini, S.; Winter, M. Dependency of aluminum collector corrosion in lithium ion batteries on the electrolyte solvent. ECS Electrochem. Lett. 2012, 1, C9. [CrossRef]

45. Bessone, J. The activation of aluminium by mercury ions in non-aggressive media. Corros. Sci. 2006, 48, 4243-4256. [CrossRef]

46. Portsmouth, R.; Gladden, L. Determination of pore connectivity by mercury porosimetry. Chem. Eng. Sci. 1991, 46, 3023-3036. [CrossRef] 
47. Olivier, J.P.; Winter, M. Determination of the absolute and relative extents of basal plane surface area and "non-basal plane surface" area of graphites and their impact on anode performance in lithium ion batteries. J. Power Sources 2001, 97, 151-155. [CrossRef]

48. Winter, M.; Novák, P.; Monnier, A. Graphites for lithium-ion cells: The correlation of the first-cycle charge loss with the brunauer-emmett-teller surface area. J. Electrochem. Soc. 1998, 145, 428. [CrossRef]

49. Börner, M.; Horsthemke, F.; Kollmer, F.; Haseloff, S.; Friesen, A.; Niehoff, P.; Nowak, S.; Winter, M.; Schappacher, F.M. Degradation effects on the surface of commercial LiNi0.5Co0.2Mn0.3O2 electrodes. J. Power Sources 2016, 335, 45-55. [CrossRef]

50. Kuila, U. Measurement and Interpretation of Porosity and Pore-Size Distribution in Mudrocks: The Hole Story of Shales. Ph.D. Thesis, Colorado School of Mines, Golden, CO, USA, 2013.

51. Markoulidis, F.; Bates, J.; Lekakou, C.; Slade, R.; Laudone, G.M. Supercapacitors with lithium-ion electrolyte: An experimental study and design of the activated carbon electrodes via modelling and simulations. Carbon 2020, 164, 422-434. [CrossRef]

52. Wieser, C.; Prill, T.; Schladitz, K. Multiscale simulation process and application to additives in porous composite battery electrodes. J. Power Sources 2015, 277, 64-75. [CrossRef]

53. Zielke, L.; Hutzenlaub, T.; Wheeler, D.R.; Chao, C.W.; Manke, I.; Hilger, A.; Paust, N.; Zengerle, R.; Thiele, S. ThreePhase Multiscale Modeling of a LiCoO2 Cathode: Combining the Advantages of FIB-SEM Imaging and X-Ray Tomography. Adv. Energy Mater. 2015, 5, 1401612. [CrossRef]

54. Cadiou, F.; Douillard, T.; Besnard, N.; Lestriez, B.; Maire, E. Multiscale characterisation of composite electrode microstructures for high density lithium-ion batteries guided by the specificities of their electronic and ionic transport mechanisms. J. Electrochem. Soc. 2020, 167, 100521. [CrossRef]

55. Jaiser, S.; Müller, M.; Baunach, M.; Bauer, W.; Scharfer, P.; Schabel, W. Investigation of film solidification and binder migration during drying of Li-Ion battery anodes. J. Power Sources 2016, 318, 210-219. [CrossRef]

56. Park, J.; Kim, K.T.; Oh, D.Y.; Jin, D.; Kim, D.; Jung, Y.S.; Lee, Y.M. Digital Twin-Driven All-Solid-State Battery: Unraveling the Physical and Electrochemical Behaviors. Adv. Energy Mater. 2020, 10, 2001563. [CrossRef] 